NBER WORKING PAPER SERIES

\title{
THE EFFECT OF FEMALE EDUCATION ON FERTILITY AND INFANT HEALTH: EVIDENCE FROM SCHOOL ENTRY POLICIES USING EXACT DATE OF BIRTH
}

\author{
Justin McCrary \\ Heather Royer \\ Working Paper 12329 \\ http://www.nber.org/papers/w12329 \\ NATIONAL BUREAU OF ECONOMIC RESEARCH \\ 1050 Massachusetts Avenue \\ Cambridge, MA 02138 \\ June 2006
}

For useful comments we thank the editor and three anonymous referees, Josh Angrist, Eli Berman, John Bound, David Card, Kerwin Charles, Ken Chay, Janet Currie, John DiNardo, Carlos Dobkin, Sue Dynarski, Michael Greenstone, Michael Grossman, Caroline Hoxby, Mireille Jacobson, Alan Krueger, Ted Joyce, David Lee, Darren Lubotsky, Paco Martorell, Enrico Moretti, Jack Porter, Jim Powell, Dahlia Remler, Gary Solon, Duncan Thomas, Dean Yang and numerous seminar participants. Royer thanks the Robert Wood Johnson Foundation for generous support. Any errors are our own. The views expressed herein are those of the author(s) and do not necessarily reflect the views of the National Bureau of Economic Research.

(C)2006 by Justin McCrary and Heather Royer. All rights reserved. Short sections of text, not to exceed two paragraphs, may be quoted without explicit permission provided that full credit, including $\odot$ notice, is given to the source. 
The Effect of Female Education on Fertility and Infant Health: Evidence from School Entry Policies Using Exact Date of Birth

Justin McCrary and Heather Royer

NBER Working Paper No. 12329

June 2006

JEL No. C3, D1, I1, J2

\begin{abstract}
This paper uses age-at-school-entry policies to identify the effect of female education on fertility and infant health. We focus on sharp contrasts in schooling, fertility, and infant health between women born just before and after the school entry date. School entry policies affect female education and the quality of a woman's mate and have generally small, but possibly heterogeneous, effects on fertility and infant health. We argue that school entry policies manipulate primarily the education of young women at risk of dropping out of school.
\end{abstract}

Justin McCrary

University of Michigan

440 Lorch Hall

Ann Arbor, MI 48109-1220

and NBER

jmccrary@umich.edu

Heather Royer

University of Michigan

109 Observatory, SPH-II, M2102

Ann Arbor, MI 48109-2029

hroyer@umich.edu 


\section{Introduction}

Education is widely held to be a key determinant of fertility and infant health. From a theoretical perspective, several causal channels have been emphasized. First, education raises a woman's permanent income through earnings, tilting her optimal fertility choices toward fewer offspring of higher quality (Becker 1960, Mincer 1963, Becker and Lewis 1973, Willis 1973). Second, under positive assortative mating, a woman's education is causally connected to her mate's education (Behrman and Rosenzweig 2002), so that the effect of education on household permanent income is augmented through a multiplier effect. Third, education may improve an individual's knowledge of, and ability to process information regarding, fertility options and healthy pregnancy behaviors (Grossman 1972).

On the empirical side, an extensive literature documents associations between education and fertility and infant health (Strauss and Thomas 1995). However, whether these associations represent causal relationships has been the subject of debate. Early quasi-experimental infant health research using differences in education between sisters who become mothers points toward more muted effects than the cross-sectional relationship, suggesting an important role for selection (Wolfe and Behrman 1987). On the other hand, more recent quasi-experimental infant health research focused on primary school construction programs in Taiwan (Chou, Liu, Grossman and Joyce 2003) and Indonesia (Breierova and Duflo 2004), and on college openings in the United States (Currie and Moretti 2003), finds that there is a causal effect, and that observational comparisons may even understate the true causal effect. Recent quasi-experimental fertility papers (Black, Devereux and Salvanes 2004, Leon 2004) similarly suggest the causal effect is as large as the partial correlation. ${ }^{1}$

In this paper, we present new evidence on the effect of female education on fertility and infant health in the United States using school entry policies as an instrument for education. In particular, we exploit the fact that the year in which a child starts school is a discontinuous function of exact date of birth. For example, in California and Texas, our two study states,

\footnotetext{
${ }^{1}$ Oreopoulos, Page and Stevens (2005) present some evidence to the contrary.
} 
children must be 5 years old on December 1st (California) or September 1st (Texas) in the year in which they begin kindergarten. As a consequence of these policies, children born within one or two days of one another enter school at different ages and have different levels of education throughout school enrollment. Because individuals born near in time are likely similar along non-education related dimensions, differences in education at motherhood for women born near these entry dates are arguably exogenous. The crux of our identification strategy is to compare fertility and infant health outcomes for mothers born just prior to, and just subsequent to, the school entry date, and to relate the magnitude of these differences to the education discontinuity.

Using large samples of birth records, we reach four key conclusions:

1. School entry policies have large effects on schooling at motherhood: one-fourth of young Texas mothers born after the school entry date have a year less education than they otherwise would, had they been born before the entry date. For California, our estimate is one-seventh.

2. Education does not significantly impact fertility: women born just before and after the school entry date are equally likely to become mothers and give birth at similar ages.

3. Education improves mating market outcomes: women born just after the entry date have younger and less educated mates than women born just before.

4. Education does not significantly impact observable inputs to infant health and has generally small, but possibly heterogeneous, effects on infant health: women born just before and after the entry date have similar prenatal behaviors, as proxied by rates of smoking and prenatal care, and give birth to children of similar health, as proxied by birth weight, prematurity, and rate of infant mortality. There is some suggestive evidence of different effects of education on low birth weight by race and ethnicity.

Implementing our identification strategy requires information on date of birth, which is unavailable on most public-use files. We use an administrative data set on all births in California and Texas from 1989 to the present with information on mother's date of birth and education, infant health, pregnancy behaviors (e.g., smoking and drinking), and paternal 
characteristics. ${ }^{2}$ These data allow us to focus contrasts narrowly around the school entry date, a challenge for earlier analyses in which either exact date of birth or large sample sizes were wanting (Angrist and Krueger 1991, Cascio and Lewis 2006).

A narrow focus on individuals born near the school entry date builds on the quarter of birth approach of Angrist and Krueger (1991). First, it sidesteps the criticisms of Bound, Jaeger and Baker (1995) regarding seasonality of birth (assuming seasonal patterns are continuous at the school entry date). Second, it leads to a precise estimate of the relationship between within-year birth timing and educational attainment, circumventing statistical problems associated with weak instruments (Staiger and Stock 1997, Moreira 2003, Andrews, Moreira and Stock 2006).

The crucial assumption underlying this approach is that for dates near the school entry date, an individual's date of birth is random. This assumption is plausible a priori, since parents are unlikely to strategically plan the exact date of birth of their child. Moreover, this assumption is testable - women born just before and after school entry dates should be similar in terms of predetermined, observable characteristics. We find that they are.

Proper interpretation of our estimates requires consideration of several features specific to our approach. First, not all children will begin school in the year predicted by school entry policies. The parents of a child born before the school entry date may hold their child back by a year, and the parents of a child born after the school entry date may petition for their child to start school a year before typically allowed, or may start their child in private school. ${ }^{3}$ For neither type of child will schooling progression be affected by school entry policies. This suggests that our estimates may disproportionately reflect the experience of women from low socio-economic backgrounds, whose parents are somewhat more likely to comply with school entry policies (Elder and Lubotsky 2006).

Second, even if school entry policies affect a woman's schooling progression, they may

\footnotetext{
${ }^{2}$ Maternal date of birth was added to the standard U.S. birth certificate in 1989, but is not included in public use birth certificate data from the National Center for Health Statistics.

${ }^{3}$ Elder and Lubotsky (2006) estimate that 93 percent of children begin school in the year predicted by statewide school entry policies. This estimate is similar to many of the estimates in Cascio and Lewis (2006).
} 
not affect education at motherhood. For example, for a woman intent on obtaining a specific level of schooling before dropping out and beginning a family, education at motherhood is unaffected by the timing of school entry. School entry policies affect education at motherhood for two types of women: those still enrolled in school and those who have already completed schooling, whose school-leaving decision was age-dependent (i.e., not just schooling-dependent). For example, a woman who drops out of school at the earliest age allowed under a typical compulsory schooling law will have fewer years of education if she starts school late (Angrist and Krueger 1992). ${ }^{4}$ This suggests that our estimates may be most relevant for women at risk of dropping out of school. Such women are likely to give birth at earlier ages than women intent on attaining a specific level of schooling, such as a college degree. Empirically, we find that school entry policies exert the greatest impact on the education of women giving birth at young ages. Thus, we stratify most of our analysis by age, focusing on women age 23 or younger, for whom our first stage relationship is strongest.

Third, if the dropout decision is affected by both current age and schooling level, and if school completion is a binding constraint on fertility timing, then we should expect to see effects of school entry policies on two factors that potentially affect infant health - education at motherhood and age at motherhood. In general, this would lead to a failure of the order condition for instrumental variables (fewer instruments than endogenous regressors), preventing consistent estimation of the effect of female education on infant health without additional instruments. However, surprisingly, we document that school entry policies affect neither the probability of becoming a mother nor age at motherhood. This suggests that for women whose dropout decisions depend on schooling level, schooling completion is not a binding constraint on fertility timing. Importantly, this also implies that our approach

\footnotetext{
${ }^{4}$ Age at school leaving laws are not the only plausible reason for dropout decisions to depend on age. Additional plausible mechanisms include a desire to begin working life, perhaps triggered by minimum work age policies (Lleras-Muney 2002), the availability of welfare, or contraceptive failure. Indeed, for some years, Texas' compulsory schooling law requires individuals to finish the grade they start when they become compulsory schooling age (Texas Education Code, Section 21.032, 1984, Section 25.085, 1995). In such a circumstance, compulsory school leaving laws do not lead to differences in education for those starting school at different times.
} 
identifies an education effect unconfounded by selection into motherhood and unconfounded by age at motherhood.

Fourth, education at motherhood may differ from completed education if women return to school after childbirth. This is important because a temporary reduction in schooling will not necessarily affect permanent household income, whereas a permanent reduction in schooling would be expected to, because of the labor market return to schooling. Schooling reductions are likely to be permanent if women find it difficult (even if desirable) to return to or complete school after having children. In the National Longitudinal Survey of Youth, school enrollment rates subsequent to birth are strongly inversely related to age at first birth. Even for those who do return to school, completion of schooling is less likely than for those not having children. These patterns are consistent with the notion that hours spent caring for children crowd out hours required to attend or study for school and suggest that for the women in our sample, schooling differences we observe at motherhood may well become permanent schooling differences. Indeed, some of our results indicate income differences between women born before and after the cutoff date, suggesting that schooling reductions may be permanent. This observation suggests that there may heterogeneity by age in the effects of education on infant health, an issue we address below, but find little evidence to support. While temporary and permanent reductions in schooling may lead to different effects on income, both temporary and permanent reductions in schooling may affect learning and the ability to process information, the causal pathway emphasized by Glewwe (1999).

The remainder of the paper is organized as follows. In Section II we describe the mechanisms by which education could affect fertility and infant health and briefly summarize the existing literature on the topic. In Section III, we discuss our identification strategy, as well as our approach to nonparametric estimation, model selection, and inference. After describing the data we use in Section IV, we present the results of our estimation in Section V. Section VI presents evidence on heterogeneous effects and discusses a variety of important interpretation issues. Section VII concludes. 


\section{Conceptual Issues}

\section{A. Why Should Education Matter?}

In broad terms, education may affect a woman's fertility and child-investment choices through either income or learning (Michael 1973). ${ }^{5}$ Education increases a woman's income stream through both the labor market and the mating market, the latter through assortative mating. In addition to the income channel, education may improve a woman's stock of knowledge regarding contraceptive technologies or healthy pregnancy behaviors, either because it augments her knowledge directly (i.e., educational curricula are important), or because it improves her ability to absorb and process information generally. We next describe each of these mechanisms in turn.

The income channel operates through the well-documented effect of education on labor earnings. In a comprehensive survey, Card (1999) concludes that by the 1990s, the causal effect of an additional year of education on annual earnings for both women and men in the United States was around 15 percent. ${ }^{6}$ The notion that an exogenous increase in a woman's income may lead to reduced fertility is present in the earliest treatments of the neoclassical model of fertility (Mincer 1963, Willis 1973). In these models, households do not value children per se, but what Willis terms "child services" - the product of the number of children and the average quality of those children. A key idea is that production of child services is time-intensive relative to other activities for the woman. As the value of a woman's time rises, she generally substitutes away from consumption that is highly timeintensive (Becker 1965) and hence desires fewer children. These predicted effects of education on fertility map naturally into predicted effects on child quality. Assuming child services are a normal good, falling fertility in response to rising income requires that child quality be

\footnotetext{
${ }^{5}$ Other potentially less important effects include the effect of education on job-related stress, operating through occupational choice.

${ }^{6}$ See Card's Table 1 and summary at p. 1855. Taking the return to education to be constant over the life cycle, this implies that an exogenous additional year of schooling raises by 15 percent an individual's present discounted value of expected income, or Friedman's (1957) concept of permanent income. Permanent income seems closest to the notion of income used in most of the early static models of fertility (see, for example, Willis (1973), pp. S22, S48, S52).
} 
an increasing function of income. Cross-price effects such as these were first emphasized by Becker and Lewis (1973) and Willis (1973). ${ }^{7}$

Predictions based on the income channel are further sharpened by positive assortative mating, or the tendency for men and women of similar education to pair (Behrman and Rosenzweig 2002). Under this type of stratification, an exogenous increase in a woman's education leads to a mate of higher education, further increasing household permanent income through a multiplier effect.

In addition to the income channel, the literature has stressed the role of education in augmenting an individual's stock of health knowledge. ${ }^{8}$ With respect to fertility, Rosenzweig and Schultz (1989) provide evidence that a woman's education explains ability to effectively use contraception. With respect to infant health, Thomas, Strauss and Henriques (1991) show that education predicts a woman's ability in regards to, or perhaps interest in, information acquisition and processing. ${ }^{9}$ One of the most frequently-cited examples is smoking (Currie and Moretti 2003). Through anti-smoking campaigns in schools or health class, children could learn about the dangers of smoking and be discouraged from adopting the habit. Glewwe (1999) argues that the most important mechanism for knowledge gain is not directly via curricula; rather the skills obtained in school facilitate the acquisition of health knowledge. Grossman (1972) formalizes these ideas by viewing education as a productivity shifter in the household production function for health.

Since education can affect infant health through several different channels and the intensity of these channels may not be the same for all levels of education nor for all subpopulations, the effect of education on infant health may differ across studies. For example, Currie and Moretti (2003) use college openings to study the effect of maternal education on infant health. The women whose schooling attainment at motherhood is affected by college openings are those women with a high level of education generally. As we show below, our

\footnotetext{
${ }^{7}$ For an early empirical examination of this trade-off using twins, see Rosenzweig and Wolpin (1980).

${ }^{8}$ See, for example, Willis (1973, p. S51)

${ }^{9}$ Kenkel (1991) argues that the Grossman effect cannot explain the entire relationship with regard to adult health.
} 
study focuses on the causal role of education for women with a low level of education generally. Educational levels that appear to be affected in our study are in the range of eighth to twelfth grade, with a muted effect on the first two years of college. This subpopulation is of interest for several reasons. First, the observational infant health return to education is declining in the level of education. Second, the labor market return to education is declining in education (Card 1999). Third, young women at risk of dropping out of school are frequently the target of specific policies aimed at reducing fertility and improving infant health.

\section{B. What Does the Effect of Education Represent?}

The model of fertility and child investment outlined above suggests that infant health is a function of (i) maternal choice variables (e.g., smoking while pregnant) and (ii) maternal endowments (e.g., genetic makeup). A general health production function takes the form $Y=f(X, W)$, where $Y$ is a measure of the health of a particular mother's newborn child, $X$ is a vector of maternal choice variables, and $W$ is a vector of maternal endowments. Elements of $W$ are fixed from the mother's perspective. However, a mother's schooling could affect her health inputs, elements of $X$. Demand for health inputs may be expressed as a general function of resources, endowments, and the demand for schooling, $X=g(S, I, W)$, where $S$ denotes schooling and $I$ denotes resources. Resources are meant to be interpreted broadly as non-schooling factors that affect a mother's choice of health inputs. One such resource is income, which may lead to higher quality prenatal care, for example. Combining, we have

$$
Y=f(g(S, I, W), W)
$$

Thus, the relationship between schooling and infant health is an admixture of the partial derivatives of the production function $f(\cdot)$ and the quasi-demand function $g(\cdot)$ :

$$
\frac{\partial Y}{\partial S}=\frac{\partial f^{\prime}}{\partial X} \frac{\partial g}{\partial S}+\frac{\partial f^{\prime}}{\partial X} \frac{\partial g}{\partial I^{\prime}} \frac{\partial I}{\partial S}
$$


This clarifies that the effect of education on infant health is inherently a reduced-form parameter summarizing (i) the impact of schooling on health inputs $\left(\frac{\partial g}{\partial S}\right)$, (ii) the impact of schooling on resources $\left(\frac{\partial I}{\partial S}\right)$, (iii) the impact of resources on health inputs $\left(\frac{\partial g}{\partial I^{\prime}}\right)$, and (iv) the impact of health inputs on infant health $\left(\frac{\partial f}{\partial X}\right)$.

The first term of equation (2) is the focus of Grossman's (1972) model of health capital. In particular, it is the effect of education on health inputs via health knowledge and the ability to process information. The second term of equation (2) represents the indirect effect of education via resources. A woman's education may affect her income and her choice of mate, which in turn could alter her choice of health inputs.

In this paper, we are unable to distinguish between the direct/Grossman effect and the indirect effect. Nevertheless, this distinction is important. It highlights the potential for heterogeneous education effects as there are several mechanisms by which education could potentially improve infant health. In the present case, the effect of education may differ considerably based on whether the mother is still enrolled in school, as discussed above.

Before proceeding, we note that analogous expressions may be developed relating female education to fertility decisions. A key difference is that a woman may be able to exercise choice over her fertility more readily than choice over the health of her offspring. This may be captured in the model above by ascribing a more limited role for genetic factors regarding fertility than regarding infant health.

\section{Methodology}

Consider a partially linear approximation to equation (1),

$$
Y=\theta S+\tau(W)+\varepsilon
$$

where $\theta$ represents the reduced-form causal parameter in equation $(2), \tau(\cdot)$ is a general mapping, and the residual $\varepsilon$ is meant to capture other factors potentially affecting infant 
health (e.g., maternal age). ${ }^{10,11}$

Identifying the effect of education on infant health, $\theta$, requires solving two difficult problems. The first problem is the endogeneity of schooling. For example, education at motherhood may be related to family background, which may be related to infant health through non-schooling mechanisms. The second problem is sample selection. Education may affect a woman's decision to have children, leading to a selected sample of those observed giving birth. The standard regression discontinuity approach will, under continuity assumptions, circumvent the endogeneity problem. However, except in unusual circumstances, it will not circumvent the sample selection problem. Problems with both endogeneity and sample selection lead to two endogenous regressors, necessitating two instruments instead of one.

To describe our solution to these two identification problems, let us for the moment ignore sample selection issues and assume that mothers are a random sample of women. Empirically, we will show that schooling is a discontinuous function of day of birth. Consider the model

$$
S=n(R)+\beta D+v
$$

where $R$ is an individual's day of birth relative to the school entry date for the state in which the individual begins school, $n(\cdot)$ is a continuous function, $D=\mathbf{1}(R>0)$, and $v$ is mean zero given $R$ (cf., Porter 2003). For example, $R=0$ for an individual born on the school entry date, and $R=5$ for an individual born 5 days after the school entry date. ${ }^{12}$ In this notation, the parameter $\beta$ measures the discontinuity in expected schooling at the school entry date, or the vertical gap at $r=0$ in the conditional expectation of $S$ given $R=r$.

Equation (4) may be thought of as the "first stage" equation in a simultaneous equation

\footnotetext{
${ }^{10}$ The additive separability in equation (3) is not critical to our approach. For example, one could instead use an approximation that included interaction terms between schooling and endowments. Richer estimation equations such as these are, however, rare in the literature.

${ }^{11}$ Factors captured in the residual may be correlated with schooling.

${ }^{12}$ All individuals born on the same day but in different years will have the same value of $R$.
} 
system, where the structural equation is given in (3). The "reduced-form" equation is

$$
Y=m(R)+\alpha D+u
$$

where $\alpha=\theta \beta$ and $u$ is an error term. ${ }^{13}$ This equation may be derived by substituting equation (4) into equation (3) and taking the conditional expectation of $Y$ given $R$.

Discontinuity in the conditional expectation of infant health at the school entry date identifies $\alpha+\lim _{r \downarrow 0} E[\tau(W) \mid R=r]-\lim _{r \uparrow 0} E[\tau(W) \mid R=r]+\lim _{r \downarrow 0} E[\varepsilon \mid R=r]-\lim _{r \uparrow 0} E[\varepsilon \mid R=r]$. This will be different from $\alpha$ generally. If the conditional distribution of $W$ given $R=r$ is continuous in $r$, then $\lim _{r \downarrow 0} E[\tau(W) \mid R=r]-\lim _{r \uparrow 0} E[\tau(W) \mid R=r]=0 .{ }^{14}$ If the conditional distribution of $\varepsilon$ given $R=r$ is continuous in $r$, then $\lim _{r \downarrow 0} E[\varepsilon \mid R=r]-\lim _{r \uparrow 0} E[\varepsilon \mid R=r]=0$. If both these conditions hold, then $\alpha$ is identified from the infant health discontinuity. In words, we assume (i) continuity of background characteristics in day of birth, and (ii) continuity of unobservable characteristics in day of birth. The first assumption is testable if background characteristics are observed. We demonstrate continuity of background characteristics in Section V, below. The second assumption is plausible on prior grounds and is partially corroborated by failure to reject tests of the first assumption.

Under these two assumptions, $\theta$ may be consistently estimated by a sample analogue to

$$
\frac{\lim _{r \downarrow 0} E[Y \mid R=r]-\lim _{r \uparrow 0} E[Y \mid R=r]}{\lim _{r \downarrow 0} E[S \mid R=r]-\lim _{r \uparrow 0} E[S \mid R=r]}=\frac{\alpha}{\beta}
$$

as emphasized by Hahn, Todd and van der Klaauw (2001). ${ }^{15}$ Thus, the regression discontinuity approach circumvents the endogeneity problem.

Consider now the problem of sample selection. We only observe infant health, $Y$, for the

\footnotetext{
${ }^{13}$ In terms of our earlier notation, $m(R)=\theta n(R)+E[\tau(W) \mid R]$ and $u=\theta v+\tau(W)-E[\tau(W) \mid R]+\varepsilon$.

${ }^{14}$ This holds even if $\tau(\cdot)$ is discontinuous. Proof available on request.

${ }^{15}$ An unaddressed issue in the regression discontinuity literature is the importance of non-classical measurement error. The results of Kane, Rouse and Staiger (1999) indicate that our estimates, which are small, likely overstate the true effect, since education is measured with non-classical measurement error and our infant health measurements are arguably free from error.
} 
subset of women who decide to become mothers. Nonetheless, we can consistently estimate population conditional expectations with the inclusion of an additively separable control function (Gronau 1974, Heckman 1976, 1979). Consider an estimation equation for the observed data, with $Y_{i j}$ denoting infant health for woman $i$ with day of birth $R_{j}$, and $P_{j}$ the conditional probability of giving birth given $R_{j}$ :

$$
Y_{i j}=m\left(R_{j}\right)+\alpha D_{j}+\lambda\left(P_{j}\right)+v_{i j}
$$

where the control function $\lambda\left(P_{j}\right)$ corrects for sample selection. The specific functional form of $\lambda(\cdot)$ depends on distributional assumptions. For example, under bivariate normality of $v_{i j}$ and the unobserved component of the decision to become a mother, $\lambda(p) \propto p^{-1} \phi\left(\Phi^{-1}(p)\right)$ or the inverse Mills ratio (Heckman 1979, Ahn and Powell 1993, Das, Newey and Vella 2003). ${ }^{16}$

Under general conditions, $\lambda(\cdot)$ is continuous. ${ }^{17}$ Continuity of $\lambda(\cdot)$ and $m(\cdot)$ imply that if the probability of motherhood is smooth in day of birth, then $\widetilde{m}(\cdot)$ is continuous, where $\widetilde{m}\left(R_{j}\right) \equiv m\left(R_{j}\right)+\lambda\left(P_{j}\right) .{ }^{18}$ We may thus rewrite equation $(7)$ as

$$
Y_{i j}=\widetilde{m}\left(R_{j}\right)+\alpha D_{j}+v_{i j}
$$

This clarifies that sample selection poses no difficulties if the probability of motherhood is unaffected by school entry policies. However, if the probability of motherhood were affected by school entry policies then $\widetilde{m}(\cdot)$ would be discontinuous and point identification would not be possible without further modeling. ${ }^{19}$ We document that the probability of motherhood

\footnotetext{
${ }^{16}$ We are able to accurately estimate $P_{j}$, despite a lack of longitudinal information, by comparing the number of women born on birthday $R_{j}$-i.e., the risk set for becoming a mother within our sampling frame - to the number of women observing becoming mothers within our sampling frame who have birthday $R_{j}$ (see Section IV, below).

${ }^{17}$ Sufficient conditions include, for example, existence of $E\left[v_{i j}\right]$ and a joint density function characterizing the distribution of the $v_{i j}$ and the residuals in the observation equation (proof available on request). Continuity of $\lambda(\cdot)$ is freely assumed in the nonparametric sample selection literature (e.g., Das et al. 2003).

${ }^{18}$ This definition is coherent since $P_{j}$ depends only on $R_{j}$.

${ }^{19}$ If there were a discontinuity in the probability of motherhood in day of birth and no instrument for observation were available, the approach of Lee (2005) could be used to bound the treatment effect.
} 
is a smooth function of day of birth (see Section V, below). This is surprising in light of the negative association between income and fertility documented in other work. Nonetheless, the substantive implication of these results is supported by our analysis of age at first birth, which shows that age at motherhood is a similarly a smooth function of day of birth.

To the best of our knowledge, school entry policies are the only educational intervention studied in the literature that do not affect fertility. This is important for two reasons. First, an effect on the probability of giving birth creates sample selection problems that would lead to bias, as discussed above. Second, an effect on age at birth would lead to ambiguities of interpretation. For example, an educational intervention inducing women to attend college would delay fertility mechanically. Since a woman delaying fertility from 18 to 22 on average improves her baby's health at birth (Royer 2004), this would lead to a failure of the order condition for instrumental variables estimation-i.e., more endogenous regressors than instruments. School entry policies are thus a unique setting in which it is possible to isolate a pure effect of education on infant health.

With only minor alterations to the discussion, the parameters $\alpha, \beta$, and $\theta$ may be cast as random variables rather than as constants in the population (cf., Card 1999, Appendix A.2). As emphasized by Hahn et al. (2001), there is a direct analogy between the probability limit of a regression discontinuity estimator and the local average treatment effect interpretation of the instrumental variables estimator. In particular, under a monotonic effect of school entry policies on schooling, a regression discontinuity estimator will identify the effect of schooling on fertility and infant health for those persons whose educational attainment is causally affected by school entry policies. As noted in the introduction, this subpopulation likely does not represent a random sample of the overall population, but rather a low socioeconomic status subpopulation at risk of dropping out of school early.

However, monotonicity is not guaranteed. The effect of school entry policies on schooling would not be monotonic if, for example, a woman's parents would choose to delay her entrance into school if she were born before the school entry date, but would choose to 
petition the school district to allow her to begin school early if she were born after the school entry date. To take another example, monotonicity would be violated if a woman would eventually complete more schooling if she were born after the school entry date, than she would if she were born before the school entry date. This could occur if, for example, being older throughout school progression made it easier to complete more schooling.

On the other hand, as emphasized by Angrist and Imbens (1995), monotonicity is partially testable, because it implies that at each point of the education distribution, the probability of attaining at least that level of education for individuals born before the cutoff date must exceed the probability for those born after the date. ${ }^{20}$ In Section V, below, we develop a regression discontinuity analogue to the estimator given in Angrist and Imbens (1995) for the average causal response weights. The results corroborate the monotonicity assumption.

Estimation of equation (8) may be accomplished in a variety of ways. The recent empirical regression discontinuity literature has focused on global polynomial estimators (see, for example, the references given in Lee and Card 2006). ${ }^{21}$ However, Hahn et al. (2001) advocate an adaptation of local linear regression, a nonparametric smoother studied in detail in the statistics literature (for an overview, see Fan and Gijbels 1996) and known to exhibit good boundary properties. ${ }^{22}$ These two procedures are generally competitive, with differing strengths and weaknesses. ${ }^{23}$

\footnotetext{
${ }^{20}$ That is, the distribution function of schooling for those born after the school entry date must lie entirely to the left (or right) of the distribution function of schooling for those born before the school entry date. The key condition is that the distribution functions cannot cross.

${ }^{21}$ The global polynomial estimator may be viewed as a nonparametric series estimator if one contemplates increasing the number of polynomial terms as the sample size grows (Pagan and Ullah 1999, Section 3.8).

${ }^{22}$ Porter (2003) presents detailed distribution theory for the estimator proposed by Hahn et al. (2001), as well as for an estimator partly inspired by Robinson (1988) that generalizes more easily to higher dimensions.

${ }^{23}$ Each procedure requires the researcher to choose a tuning parameter. For global polynomial regression, one must choose an order of polynomial and whether to allow the polynomials to differ depending on the side of the discontinuity. For local linear regression, one must choose a bandwidth. Each approach has its strengths. For the global polynomial estimator, one strength is that its implementation is simple; a second is that it is easy to conduct hypothesis testing and goodness-of-fit tests such as those conducted in Lee and McCrary (2005); and a third is that there exists a simple data generating process for which the global polynomial estimator is the maximum likelihood estimator. For the local linear estimator, one strength is that it is more flexibile in accomodating regression functions of various shapes. This flexibility is reflected in the impressive minmax efficiency of the local linear estimator (Fan and Gijbels 1996). A second strength is that the local linear asymptotic thought experiment of a shrinking bandwidth sequence is more tightly linked to the general regression discontinuity thought experiment than the global polynomial asymptotic
} 
We estimate equation (8) using local linear regression in a two-step procedure. The first step is a simple least squares regression of $Y_{i j}$ on day of birth fixed effects (i.e., fixed effects for each $R_{j}$ ) and background characteristics of the mother which are smooth functions of $R_{j}$-(i) the year of the administrative data set, (ii) the mother's race and ethnicity, and (iii) the mother's age. We include these background controls for variance reduction only. ${ }^{24}$ Then, using the day of birth fixed effects from the first step, we estimate the conditional expectation using local linear regression. ${ }^{25}$

Let $\bar{Y}_{j}$ denote the fixed effect coefficient corresponding to $R_{j}$ coming from the first step. Then our estimator for $\alpha$, the effect of school entry policies on $Y_{i j}$, is the coefficient estimate on $D_{j}$ in the weighted least squares regression

$$
\min _{\left(\alpha, \pi_{0}, \pi_{1}, \pi_{2}\right)} \sum_{j=1}^{J}\left\{\bar{Y}_{j}-\alpha D_{j}-\pi_{0}-\pi_{1} R_{j}-\pi_{2} D_{j} R_{j}\right\}^{2} K_{h}\left(R_{j}\right)
$$

where $K_{h}(t)=h^{-1} K(t / h)$ with the boundary optimal kernel $K(t)=\max \{0,1-|t|\}$ (Cheng, Fan and Marron 1997) and $h$ is the bandwidth. ${ }^{26}$ Because the local linear regression is simply a weighted least squares regression at the grouped level, accurate inference under mild assumptions is available from White's (1980) variance estimator at the group level. ${ }^{27}$ This is analogous to estimating a grouped regression at the group level (Wooldridge 2003).

The discontinuity in schooling, $\beta$, may be estimated similarly. The ratio of the infant

thought experiment of an increasing order of polynomial.

${ }^{24}$ This is analogous to standard practice with randomized controlled trials (cf., Katz, Kling and Liebman 2001).

${ }^{25}$ This is a simple strategy for estimating a partially linear model (cf., DiNardo and Tobias 2001, Yatchew 1997, and references in Porter 2003). As estimates of the coefficients on the background characteristics are $\sqrt{n}$-consistent (Robinson 1988), whereas the main objects of our interest are $\sqrt{n h}$-consistent (where $h$ is a bandwidth parameter), the first-step estimation does not affect our second-step standard error calculations (Newey and McFadden 1994, Section 6.2).

${ }^{26}$ More generally, the entire conditional expectation of $Y_{i j}$ given $R_{j}$ may be estimated by looping through potential evaluation points $r$. For each specific $r$, the estimate of the conditional expectation is given by the constant from a weight least squares regression program similar to that given in equation (9) but with $\alpha=\pi_{2}=0, R_{j}$ replaced by $R_{j}-r$, and $K_{h}\left(R_{j}\right)$ replaced by $K_{h}\left(R_{j}-r\right)\left\{\mathbf{1}(r>0) D_{j}+\mathbf{1}(r \leq 0)\left(1-D_{j}\right)\right\}$. This is the procedure we use to produce nonparametric curve estimates, such as those in our figures.

${ }^{27}$ We also adjust our standard errors by the Lee and Card (2006) correction factor, altered to reflect our use of local linear techniques. However, this affects our standard error calculations only for the probability of motherhood, partially corroborating the fit of our local linear models. 
health to the schooling discontinuity estimates the causal the effect of schooling on infant health for compliers, and the delta-method leads to accurate inference (Porter 2003). ${ }^{28}$

To implement our second-step local linear procedure, we must specify the bandwidth, $h$. There are many automatic bandwidth selectors for nonparametric regression. Fan and Gijbels (1996, Section 4.2) provide a simple automatic procedure for the local linear regression context, and we use this procedure as a guide (see Appendix Table 1). ${ }^{29}$

All automatic selectors strive to select a bandwidth that minimizes the mean squared error of the estimator. However, for inference procedures, it is not desirable to use mean squared error minimizing bandwidths (Pagan and Ullah 1999). Intuitively, minimizing the asymptotic mean squared error with a biased estimator involves accepting asymptotic bias in order to reduce asymptotic variance. The bias leads to bad centering of confidence regions and poor coverage rates. Because of this, the standard approach to inference in a nonparametric setting is to choose an under-smoothed bandwidth, following Hall (1992). ${ }^{30}$ We use the Fan and Gijbels selector for the purposes of curve estimation (in our figures), but opt for a more conservative, under-smoothed bandwidth of 50 days for hypothesis testing for the reasons noted above. While standard errors are of course decreasing in the bandwidth, our point estimates are not very sensitive to differing bandwidth choices, over a reasonable range (see Appendix Figure 1, described below).

\footnotetext{
${ }^{28}$ Implementation requires an accurate estimate of a covariance term. We stack female education and infant health fixed effects into a 732-vector and solve a weighted least squares program similar to that in equation (9), but with the regression function fully interacted with block (8 parameters total), so that separate estimates of the discontinuity in education and infant health are available from a single regression. Use of a clustered variance estimator, clustered at the level of the 366 original observations, allows for accurate estimates of the variances and the covariance in this context.

${ }^{29}$ Adapted to the regression discontinuity setting, this procedure fits a fourth-order global polynomial separately on the left and the right of the point of discontinuity. For either side, the rule-of-thumb bandwidth is $c\left[\check{\sigma}^{2}(b-a) / \sum \check{m}^{\prime \prime}\left(R_{j}\right)^{2}\right]^{1 / 5}$ where $\check{\sigma}^{2}$ is the mean squared error for the regression, $b-a$ is the range of $R_{j}, \check{m}^{\prime \prime}\left(R_{j}\right)$ is the estimated second derivative of the global polynomial evaluated at $R_{j}$, the summation is over the data, and $c \doteq 3.438$ is a constant that depends on the kernel (see equation (4.3) of Fan and Gijbels (1996), but note also equations (3.20) and and (3.22)).

${ }^{30} \mathrm{See}$, for example, the discussion in Horowitz (2001).
} 


\section{Data and Sample}

We use confidential 1989-2001 Texas and 1989-2002 California natality data, acquired from each state's Department of Health. We focus on recent natality data since the standard birth certificate started collecting the mother's exact date of birth beginning in 1989. Information on the mother's exact date of birth is suppressed on the public-use national Natality Detail Files compiled by the National Center for Health Statistics. By special permission we obtained access to a version of the California and Texas data files with this information.

These natality files cover the universe of all births occurring in these states, approximately 800,000 births per year. At birth, each mother along with her health care provider completes an extensive survey, which inquires about maternal and paternal demographic characteristics, maternal behaviors during pregnancy (e.g., prenatal care), and the health of the infant at birth. For Texas, but not for California, our natality data are merged with infant mortality information from death certificates for those infants who died within the first year. ${ }^{31}$

We impose three main sample restrictions. First, our sample consists exclusively of mothers born in the state in which they gave birth. ${ }^{32}$ Second, for our infant health analysis, we limit our sample to mothers who are 23 years old or younger. ${ }^{33}$ When analyzing the probability of motherhood or age at birth, we make no age restriction, as we first need to verify that there is no effect on either before conditioning on age. Third, we focus on first-

\footnotetext{
${ }^{31}$ The quality of the data may vary across states. The California data do not include information on maternal drinking or infant mortality, and smoking and sexually transmitted diseases (STDs) are likely measured with greater accuracy in the Texas data. For example, in Texas, women are asked explicitly whether they smoked during pregnancy. In contrast, in California, maternal smoking must be inferred from a single question recording a variety of pregnancy conditions, including smoking. The question uses a series of numeric codes to describe these conditions. As an example, three such codes pertain to tobacco use, premature labor, and amniocentesis, which are arguably unrelated conceptually. Mothers self-report up to 16 such conditions (from among 30 possible codes). Smoking's measurement is thus very indirect. As we will see, the measured rate of California maternal smoking is only one-third that for Texas, suggestive of underreporting. To the extent that measurement errors are smooth in day of birth, our discontinuity estimates should not be affected.

${ }^{32}$ An ideal analysis would use information on the state in which a mother began her education. We view state of birth as a reasonable proxy for the state where education begins. According to the 2000 Census, 89.5 percent of 5 year olds born in California still lived in California, and 89.8 percent of 5 year olds born in Texas still lived in Texas.

${ }^{33}$ The education discontinuity induced by school entry policies is smaller for older women, as noted above.
} 
time mothers. As emphasized by Wolpin (1997), poor infant health at first birth may causally affect a woman's decision regarding subsequent fertility and child investment choices. In the absence of additional modeling, it will not be possible to separate the effect of education from the effect of the observed health of the first child. Analyzing first births also strengthens the plausibility of independence assumptions and leads to a more homogeneous sample that is more comparable to those used in the literature.

Our other sample restrictions affect the estimation sample only slightly. We exclude non-singleton births as the meaning or significance of infant health measures such as low birth weight may vary by plurality. ${ }^{34}$ Finally, we purge all mothers missing information on education and day of birth, the two main necessary elements of our research design. ${ }^{35}$

Table 1 provides descriptive statistics for our study states. Throughout most of our analysis, we examine Texas and California separately. To get a sense of how selective is our main estimation sample, we present summary statistics for the overall sample of mothers with singleton births (first column) and the sample of first-time mothers with singleton births (second column) in addition to our young mothers sample, the sample used in our main analysis (third column).

Relative to both all mothers and first-time mothers, our estimation sample is negatively selected. The first-time young native mothers are considerably younger, have lower levels of education, and worse birth outcomes. Compared to California mothers, Texas mothers have reduced number of years of schooling, are younger, and have a higher incidence of low birth weight birth, but nearly equal likelihood of a premature birth. In terms of race and ethnicity, African American mothers comprise 14 percent of our main estimation sample for California and 19 percent of that for Texas, and for both states nearly 40 percent of the mothers in our main estimation sample are Hispanic.

For our analysis of the probability of motherhood, we merge the number of first-time

\footnotetext{
${ }^{34}$ For instance, the birth weight of most twins is below average, but this is not often viewed as an indicator that the infant has a health risk. Singleton births comprise approximately 98 percent of all births.

${ }^{35}$ Mother's education and date of birth are present in 98 percent of all cases.
} 
mothers in our birth certificate data born in California (Texas) between January 1, 1969, and December 31, 1988, with the number of women born in California (Texas) on those same dates, calculated from the public-use Natality Detail Files, 1969-1988. ${ }^{36}$ The number of women in the birth certificate data relative to the number of women at risk for being observed in the birth certificate data estimates the probability of motherhood. ${ }^{37}$

\section{Results}

We present our results in six subsections. First, we examine the impact of school entry policies on education at motherhood. These effects are visually apparent, economically important, and precisely estimated. Second, we consider the impact of school entry policies on fertility. We find no difference in fertility behaviors for those born just before and after the cutoff dates. Third, we examine the impact of school entry policies on infant health, as proxied by birth weight, gestational length, and infant mortality. We find little evidence of differences in these outcomes for those born just before and after the cutoff dates. Fourth, we present instrumental variables estimates of the effect of female education on infant health. Fifth, we examine the impact of school entry policies on several risk factors for poor infant health. Sixth, we discusss robustness. The final subsection discusses age-for-grade effects.

\section{A. School Entry Policies and Education}

We begin with a graphical presentation of the effect of school entry policies on education at motherhood. Figure 1 plots the relationship between schooling and day of birth separately for California and Texas. ${ }^{38}$ In both panels, the solid line in the figure is based on the local linear smoother described in Section IV, above, and uses the automatic bandwidth procedure of Fan and Gijbels (see Appendix Table I). The open circles are fixed effects for each possible

\footnotetext{
${ }^{36}$ For these years only, the infant's date of birth is reported in the public-use files.

${ }^{37}$ To provide for an equal follow-up period regardless of day of birth, we restrict the analysis to those women in our birth certificate data giving birth after their birthday in 1989 and before their birthday in 2001 (Texas) or 2002 (California).

${ }^{38}$ For the relevant sample period and cohorts, there were no changes to the school entry date.
} 
day of birth (i.e., 366 circles, including February 29, see Section III).

We highlight two aspects of the estimates in Figure 1. First, for young mothers in both California and Texas, there is a marked discontinuity in education at motherhood exactly at the school entry date, as expected. Second, there is no evidence of a discontinuous relationship at any other day of birth. For example, we see no discontinuity at December 1 for Texas or September 1 for California. The juxtaposition of the smoothness of the conditional expectation away from the school entry date and the sharpness of the discontinuity at the entry date supports the interpretation of the education discontinuity as directly attributable to school entry policies.

Discontinuity point estimates are given in Table 2. The estimate for California is -0.15 , while that for Texas is -0.23 . These magnitudes are large relative to other benchmark differences. For example, according to the 2000 Census, the national black-white education gap for women is $-0.88 .{ }^{39}$ To interpret the magnitude of the education discontinuities, suppose that school entry policies affect schooling by one year or not at all (i.e., being born after the school entry date reduces schooling by at most one year). Under this assumption, the education discontinuity estimates the fraction of young women whose education at motherhood is affected by school entry policies (cf., Angrist and Krueger 1992). Thus, school entry policies affect education at motherhood for a large 15 (23) percent of young first-time native mothers in California (Texas). Unreported results for first-time mothers of all ages imply that school entry policies affect education at motherhood for 10 (15) percent of first-time native mothers in California (Texas). In addition, estimates of the impact of school entry policies for young women are precise, with t-ratios ranging from 7 to 24 .

As discussed, an interesting pattern in the data is that the education discontinuity is strongest for the youngest mothers and weakest for the oldest mothers. Figure 2 provides separate education discontinuity estimates for each age at birth from 15 to 35 . We supplement these disaggregated discontinuity estimates with female school enrollment rates for our

\footnotetext{
${ }^{39}$ Education in years inferred from degree-based education question, and sample restricted to women born in the U.S., aged 25-60, with unallocated values for age, sex, race, education, and place of birth.
} 
two study states, calculated from the 5 percent 2000 public-use microsample. The figure shows discontinuity estimates that decline in magnitude with age as enrollment rates fall.

The age gradient in the education discontinuities is consistent with two stories. One story is that, for women in the cohorts we study, school entry policies have no impact on completed education, but do manipulate education at motherhood for those whose pregnancy interrupts their schooling. A second story is that, for women in these cohorts, young mothers are those who drop out of school as soon as possible, and that older mothers are those whose educational attainment would not be affected by when they started their schooling because they stop schooling based on completed schooling rather than age.

Under the first story, our fertility and infant health estimates are due to the direct/Grossman effect of education. Indirect effects of education through income will not be as relevant because a woman who anticipates returning to and finishing school will have approximately equal permanent income as a woman who completes that same level of schooling prior to beginning her family. The direct/Grossman effect is operative, however, because one cannot know what one has not yet learned. Under the second story, our fertility and infant health estimates are due to both a direct/Grossman effect and an indirect effect. ${ }^{40}$ The second story thus implies a stronger effect of education on fertility and infant health than the first.

An important issue for further interpretation of our estimates is the education level at which school entry policies have the biggest effect. This issue is addressed by the curve presented in Figure 3, which Angrist and Imbens (1995) term the average causal response weighting function. ${ }^{41,42}$ The curves are essentially the difference, at each point in the educa-

\footnotetext{
${ }^{40}$ It is possible that the women whose educational attainment at motherhood is affected by school entry policies have little foresight regarding their permanent incomes. For example, some of these women may be too young to have ever received any earnings. If such women do not have sufficient foresight, then the effect of education would operate primarily through a learning channel.

${ }^{41}$ This curve is computed as follows. By analogy with the $\bar{Y}_{j}$ from above, let $\bar{S}_{j}^{s}$ denote the fixed effect coefficient on $R_{j}$ from the first-step regression, replacing $Y_{i j}$ with an indicator for having less than or equal to $s$ years of schooling. For each $s$, Figure 3 gives the estimated coefficients on $D_{j}$ in the local linear model (9), where the dependent variable is $\bar{S}_{j}^{S}$.

${ }^{42}$ Following Angrist and Imbens (1995), we report pointwise confidence intervals for the curve. It is also straightforward to use the approach of Angrist, Chernozhukov and Fernandez-Val (2006) to obtain uniform confidence bands. Practically in this context, uniform confidence bands amount to replacing twice standard error bands with roughly thrice standard error bands.
} 
tion distribution, in the cumulative distribution function for individuals born after the cutoff date versus that for individuals born before. The height of this curve at $s$ gives the fraction of the population who in the absence of school entry policies would have had less than or equal to $s$ years of schooling, but who in the presence of school entry policies would have more than $s$ years of schooling. If we assume that school entry policies manipulate schooling by at most one year, then the height of the curve at 11, for example, gives the fraction of the population whose schooling is moved from 11 to 12 years. Under this assumption, being born before the school entry date induces 3.9 (5.4) percent of California (Texas) women to have at childbirth a high school degree that they would otherwise not have. Similarly, being born before the school entry date induces 4.1 (5.4) percent of California (Texas) women to have one more year of college than they otherwise would have. Thus, Figure 3 indicates that school entry policies affect not just the number of years of high school a woman has completed by the time of her first births, but also the number of years of college.

As noted above, if school entry policies monotonically affect schooling, then the distribution functions of schooling for those born just before and after the school entry date should not cross. This pattern is corroborated by Figure 3, because the curve is positive throughout the support of education for both California and Texas.

\section{B. School Entry Policies and Fertility}

The effect of education on fertility could manifest itself in terms of the probability of ever becoming a mother, the number of children, and the timing of childbearing. As discussed below, for several cohorts of women we observe a direct estimate of the probability of becoming a mother. We do not observe completed fertility, as our sample frame is too short. However, we observe age at birth, a fertility timing measure.

Estimates of the probability of motherhood are presented in Figure 4, along with an inset figure giving the same probabilities, but for each possible birthdate from January 1, 1969 to December 31, 1988. The figure indicates no break in behavior at the school entry date. This 
impression is corroborated by the estimated discontinuities in the probability of motherhood at the school entry date (Table 2), which are economically small and statistically indistinct from zero. We note that if education affected motherhood in the direction predicted by the observational relationship, the probability of motherhood should be higher to the right of the cutoff date than to the left. ${ }^{43}$

We turn now to the effect of school entry policies on age at birth (Figure 5). We consider all first-time native mothers (i.e., we do not restrict the sample to those aged 23 or younger) since age at motherhood is possibly manipulated by school entry policies. The results are substantively similar to those regarding motherhood - there is little visual evidence of a discontinuity in age at the entry date. The point estimates for the discontinuity (Table 2) are small and statistically insignificant. ${ }^{44}$

In summary, we find little evidence that school entry policies affect either the probability of motherhood or age at first birth. This conclusion has both substantive and statistical implications. Substantively, the lack of impact of school entry policies on these fertility outcomes indicates a limited causal role for education in a woman's fertility planning, for those women desiring to have a family young enough that schooling is potentially a binding constraint on age at first birth. For example, these results are consistent with a biological model in which age of menarche, not educational attainment, determines sexual activity and in which contraception is essentially random. ${ }^{45}$ Statistically, the lack of an impact of school

\footnotetext{
${ }^{43}$ That the pattern is, if anything, negative rather than positive at the school entry date is particularly surprising in light of the potential bias of migration. If education increases the probability of emigration out of our two study states, as would be expected given the raw correlation of education and mobility, we will be more likely to observe mothers born after the cutoff date. We therefore conclude that neither mobility nor motherhood is affected causally by education for the women affected by school entry policies.

${ }^{44}$ Although school entry policies do not affect average age at motherhood, they could nonetheless affect the likelihood of giving birth at different ages (i.e., the distribution of age at motherhood). A natural method for assessing this is to estimate the discontinuity in the probability of giving birth at age $a$ or earlier, for a range of values $a$, as in our analysis of the distribution of education changes summarized in Figure 3 . These results are consistent with the hypothesis that school entry policies have no effect on any point in the age distribution (results available from authors).

${ }^{45}$ The patterns in Figure 4 could also be consistent with a model in which women born after the cutoff date are more likely to become pregnant but also more likely to obtain an abortion than women beforn before the date. While we cannot directly test this hypothesis as we have no direct data on abortions, women in our sample born just before and after the cutoff date report similar numbers of prior pregnancies (results available from authors).
} 
entry policies on fertility means that women born just before and after the school entry date form an equivalently selected sample and hence can be used to study the effect of education on infant health without sample selection corrections.

\section{School Entry Policies and Infant Health}

We begin our analysis of infant health with an examination of reduced-form effects on the incidence of low birth weight, a widely-cited risk factor for poor infant health (Figure 6). ${ }^{46}$ As with our analysis of education, we report results for mothers 23 years old or younger.

Because schooling declines at the school entry date, we expect to see an increased likelihood of low birth weight at the school entry date. However, the data indicate no break in behavior. This visual impression is confirmed by the point estimates reported in Table 2, which are generally small and statistically insignificant. The effect for California (Texas) is $-0.0003(-0.0043)$, which is small relative to the overall incidence of low birth weight for this sample of mothers (see means in Table 1). ${ }^{47}$

We next consider the impact of school entry policies on the incidence of premature birth, defined as gestational length of less than 37 weeks. Figure 7 gives an estimate of the conditional expectation of prematurity in day of birth. Because prematurity is a negative health outcome, we expect to see a rise in prematurity at the school entry date. However, the data indicate no break in behavior. The estimated discontinuities are again small and statistically insignificant (Table 2). The estimate for California is -0.00004 , while the estimate for Texas is -0.0018. These are small compared to the overall incidence of prematurity (Table 1). ${ }^{48}$

For Texas, information on infant mortality is available. The plot of infant mortality against day of birth (available upon request) provides little visual evidence of discontinuity at the school entry date. However, this may be due to low statistical power-infant mortality

\footnotetext{
${ }^{46}$ See Almond, Chay and Lee (2005) for references.

${ }^{47}$ In unreported results, similarly small and insignificant effects are estimated for the incidence of very low birth weight (birth weight less than 1500 grams), very very low birth weight (birth weight less than 1000 grams), and high birth weight (more than 4000 grams).

${ }^{48}$ As with the effects for low birth weight, we have examined the effects for a variety of cutoffs (20 weeks, 25 weeks, etc.) and found no effects for these other cutoffs.
} 
is only one-tenth as likely as low birth weight or premature. Consistent with this, the estimated discontinuity is large in economic terms (0.0013 compared with an overall incidence of 0.0067$)$, but statistically indistinct from zero.

\section{The Effect of Education on Infant Health}

To understand the magnitude of the reduced-form effects, we now turn to instrumental variables estimates. These estimates are reported in Table 3 for infant health outcomes of low birth weight, prematurity, and infant death (Texas only).

The low birth weight estimate for California (Texas) is $0.0022(0.0183)$, with a standard error of 0.0149 (0.0111). As discussed above, these estimates are the opposite of the expected sign. As a matter of comparison, Currie and Moretti's (2003) analogous estimate is -0.01. It should be noted that we have reason to believe the parameters identified by the two studies are different, a point elaborated on in the discussion section, but as a means of gauging the size of our estimates, we find this a useful contrast.

Pooling our low birth weight estimates for California and Texas provides an overall estimate for the two states with greater precision. The pooled estimate is 0.0126 (standard error of 0.0089). ${ }^{49}$ At the 5 percent level, our pooled estimate rules out the point hypothesis of -0.01 , and in fact rules out any point hypothesis more negative than $-0.002 .{ }^{50}$ Because the pooled estimate is over-identified, we also report a test of the over-identifying restrictions (in brackets). This test statistic is distributed chi-square with 1 degree of freedom under the null hypothesis of a common effect in California and Texas. The value of the test statistic, 0.75, provides little evidence against the null ( $\mathrm{p}$-value of 0.39 ).

For prematurity, estimates for both states are smaller in magnitude and estimated with somewhat less precision. The estimate for California (Texas) is 0.0002 (0.0076) with a standard error of 0.0209 (0.0133). In contrast, the Currie and Moretti estimate is -0.01 . The pooled estimate of the effect of female education on prematurity is 0.0055 (standard error

\footnotetext{
${ }^{49}$ These are efficient minimum chi-square estimates.

${ }^{50}$ We rely on a one-sided test, which is appropriate in this context.
} 
of 0.0112 ). At the 10 percent level, this estimate rules out the point hypothesis of -0.01 . At the 5 percent level, we rule out point hypotheses more negative than -0.013 . The test of over-identifying restrictions provides little evidence against the null (p-value of 0.77 ).

For infant death, we only have information for Texas. As noted above, this estimate is of the expected sign and is large in economic magnitude, but is also estimated with very little precision. If the lower edge of the confidence region were the true parameter, then infant mortality could be eliminated by a one-year increment to schooling.

We note that much more precise estimates are available if we are willing to assume that individuals born at all different times of the year are exchangeable. ${ }^{51}$ These estimates are likewise small and statistically indistinct from zero, and moreover are not statistically distinct from the estimates we report. ${ }^{52}$ However, the identifying assumption underlying these estimates is called into question by variation in predetermined characteristics over the seasonal cycle (results available on request).

\section{E. School Entry Policies and Risk Factors}

As emphasized in the theoretical discussion in Section II, the effect of female schooling on infant health is an admixture of a mother's behavioral response to schooling and the effect of her behavior on the health of her child. For this reason, it is important to attempt to flesh out which causal pathways from education to infant health are implicated by our analysis. This may be particularly important in comparing our results to those in the literature, as it is not necessarily clear what the effect of education is supposed to represent.

To learn about these causal pathways, we estimate both reduced-form estimates of the impact of school entry policies on risk factors for poor infant health (Table 2). The risk factors we consider may be thought of as falling into three key categories. The first category, which we term "risky maternal behaviors", encompasses maternal smoking, maternal drinking, and

\footnotetext{
${ }^{51}$ Practically, these estimates may be implemented as instrumental variables estimates using polynomials in $R_{j}$ and $D_{j}$ as instruments for schooling.

${ }^{52}$ As well, Sargen over-identification tests fail to reject for these estimates (Davidson and MacKinnon 2004, Section 8.6).
} 
maternal sexually transmitted diseases. The second category is comprised of several prenatal care measures. These are whether the mother obtained prenatal care at any point during her pregnancy, whether she obtained prenatal care during the first trimester, and the number of prenatal care visits she had. The third category of risk factors pertain to the quality of the infant's father, as proxied by involvement with birth, age, and education. ${ }^{53}$

Estimated impacts of school entry policies on maternal behavior (Table 2) are small, of mixed sign, and generally statistically insignificant. For example, impacts on maternal smoking in California and maternal drinking in Texas are both slightly significant, but do not share sign. ${ }^{54}$ The remaining four estimates are insignificant.

Five of the six estimates for prenatal care are of the expected sign - mothers with less education are less likely to receive prenatal care, less likely to receive it early, and receive less of it. However, the estimates are of extremely modest magnitudes (see Table 1) and only the Texas estimate for care in the first trimester reaches statistical significance.

In contrast, paternal quality effects are sizable. These estimates show that women born just subsequent to the school entry date have mates who are younger and less educated, on average, than the mates of women born just before the entry date. The point estimates for both California and Texas are large and statistically distinct from zero.

\section{F. Robustness}

Our identification of the effects of female education hinges on the assumption that women born before and after the cutoff dates are exchangeable with respect to pre-determined characteristics. This motivates tests of continuity of pre-determined characteristics in day of birth. Because assignment to starting grade occurs early in the lifecycle, pre-determined

\footnotetext{
${ }^{53}$ As a proxy for involvement, we use an indicator for whether the birth certificate contains father's date of birth and educational attainment.

${ }^{54}$ Our effects on smoking are generally inconsistent with a large literature showing strong effects of education on smoking (e.g., de Walque 2004). However, nearly all of this literature focuses on the overall population rather than just mothers. Women who smoke during pregnancy may be more likely to be addicted to smoking than those in the general population and their smoking behavior may be less affected by interventions.
} 
characteristics are essentially limited to those measured at birth. Aside from the limited characteristics such as race which are the same over time, maternal characteristics we observe in birth certificate data could be viewed as a response to assignment to starting grade and therefore are not useful for testing the research design.

However, we may test for continuity of a variety of pre-determined characteristics using the public-use Natality Detail Files from 1969-1988, which record information on infants and their parents as of birth. For mothers born 1969-1988, we can thus verify the smoothness of a variety of maternal and grandparental characteristics. ${ }^{55}$ Table 4 gives estimated discontinuities for selected pre-determined characteristics of mothers. Each entry is a discontinuity estimate for a different pre-determined characteristic, calculated in the same manner as for those in Table 2, but using no auxiliary controls.

Scanning across the columns, we find little evidence of any discontinuity in the maternal characteristics we measure: fraction Hispanic, fraction black, low birth weight and prematurity. ${ }^{56}$ Table 4 also contains a variety of tests of smoothness of grandparental characteristicsnative born mother, parity, child mortality, and maternal and paternal age- based again on the public-use Natality Detail Files from 1969-1988. ${ }^{57}$ For both California and Texas for each of these outcomes, we fail to reject the null hypothesis of continuity.

A final point regarding robustness pertains to bandwidth selection. We summarize the sensitivity of our key findings to bandwidth selection in Appendix Figure 1. This figure lists impacts of school entry policies on schooling, low birth weight, and prematurity for both states for bandwidths ranging from 50 to 100 days. The figure shows that the magnitudes reported in Table 2 are consistent with a wide range of bandwidth choices.

\footnotetext{
${ }^{55}$ More accurately, we can verify the smoothness of these characteristics for those in the risk set for becoming mothers in our sample. It is not possible to directly match the individual mothers in our sample to those in the public-use data.

${ }^{56}$ Maternal education was not included on the California and Texas birth certificates until 1989, so we are unable to conduct the specification test for that variable.

${ }^{57}$ We proxy child mortality by the fraction of the grandmother's live-born children who were still living at the time of the mother's birth.
} 


\section{G. Age-for-Grade Effects}

Our research design implicitly compares women who are old for their grade (i.e., those born immediately following the school entry cutoff date) with women who are young for their grade (i.e., those born immediately preceding the date). A child's relative maturity arguably could affect academic performance and behaviors, and thereby, potentially explain why we find small and insignificant effects of education on fertility or infant health.

While we cannot entirely rule out this hypothesis, we argue against it on several grounds. First, for both California and Texas, we find small and insignificant differences in the probability of becoming a mother, age at first birth, or infant health. Stipulating that the age-for-grade effect was of the opposite sign of the education effect, it would be surprising if, in each of these contexts, the effects were close enough in magnitude as to be small on average. Moreover, at least for fertility, the direction of bias to an age-for-grade effect is theoretically ambiguous. On the one hand, being old for one's grade could affect social development. In this case, the age-for-grade effect could be protective against pregnancy, with mature girls resisting the advances of persuasive boys. On the other hand, being old for one's grade could make pregnancy more likely if older girls are more popular than younger girls and if sexual activity is increasing in popularity. ${ }^{58}$ If the sign of the age-for-grade effect is not necessarily the opposite of the schooling effect, then equal and offsetting age-for-grade and education effects are particularly unlikely.

Second, existing estimates of the benefits postponing entrance into kindergarten are sometimes detrimental, usually small, and declining with age (Stipek (2002) reviews 26 studies). For educational outcomes, Datar (2006) finds short-run positive effects of being old for one's grade, and Bedard and Dhuey (2006) find long-run positive effects of being old for one's grade. However, we know of no research on age-for-grade effects on fertility or infant health.

Even if both education and age-for-grade effects are operative, our empirical results

\footnotetext{
${ }^{58}$ In addition, within a grade, younger girls may look up to older girls and mimic their behaviors. Mimicry renders ambiguous the sign of the age-for-grade effect, because of dependence on the magnitude of the pure age effect. Similar ambiguities surround age-for-grade effects on behaviors, such as maternal smoking.
} 
continue to have an interpretation as the program evaluation of postponing schooling as it pertains to fertility and infant health. This policy evaluation is relevant both to the private decisions of parents contemplating when their children should start school, as well as to the current debate regarding the appropriate entry date. Several states have recently moved, or are currently debating moving, these dates from late in the year to the early Fall (Datar 2006), with the stated rationale of raising the age of the average kindergartner (Aizenman 2002). While starting children at older ages may help them cope with the demands of an increasingly rigorous kindergarten curriculum, our results suggest that, for some girls, doing so makes it more likely that pregnancy will interrupt school progression at an earlier grade. To the extent that these schooling differences will be permanent, our results suggest this will lead to reduced completed schooling, mates of lower education and earnings ability, and diminished lifetime income..$^{59}$

\section{Discussion}

Our results suggest that increases in female education lead to small and statistically insignificant changes in fertility choices and infant health, a great contrast with the findings of Currie and Moretti (2003), arguably one of the more comparable studies to our own. Using openings of two- and four-year institutions in a woman's county at age 17 as an instrument for education, Currie and Moretti (2003) conclude that female education has a substantial influence on infant health and fertility patterns for white women. They find that a one year increase in education reduces the incidence of both low birth weight and prematurity by one percentage point. ${ }^{60}$ Our estimates are generally inconsistent with these large effects.

\footnotetext{
${ }^{59}$ Our estimates are most closely tied to a policy involving adjusting the school entry date by a small margin (e.g., from December 1 to November 30). Ideally, we would like to forecast the effects of a policy which adjusts the school entry date by a larger margin (e.g., from December 1 to September 1, in line with recent policy changes). It is more difficult to ascertain the effect of a large change in the school entry date, because doing so alters not just one's own age at school entry, but also the distribution of the age of one's peers. However, this is a more challenging identification problem (Manski 1993, 1995, 2000) and one we do not address in this paper.

${ }^{60}$ Currie and Moretti's (2003) effect sizes are generally similar to, or perhaps slightly smaller than, those in the broader literature on the effect of female education on infant health (e.g., Chou et al. 2003).
} 
However, the effect of female education on infant health is plausibly heterogeneous for a variety of reasons: (i) background characteristics, such as race; (ii) the level of schooling manipulated, such as high school versus college; (iii) the mechanisms by which schooling affects infant health, such as via a direct/Grossman effect or an indirect effect; (iv) the persistence of the schooling differences induced, since the behavior of forward-looking individuals may depend on both current and future human capital; and (v) the type of policy manipulation, such as school entry policies which manipulate when a child begins school, versus school exit policies which manipulate when a child ends school. This section elaborates on each of these potential sources of heterogeneity.

First, schooling interventions may not necessarily impact all subpopulations equally. For instance, Currie and Moretti (2003) document effects of college openings on white women's schooling, but note that there is little to no effect on black women's schooling. ${ }^{61}$ To investigate this possibility, Table 5 presents estimates of the effect of school entry policies on schooling, low birth weight, and prematurity, separately by race/ethnicity. ${ }^{62}$ The table indicates generally statistically similar effects on all three outcomes in both states. For example, for both states, the effect on education is somewhat smaller for black women than it is for the other two groups, but for neither state are the effects by race/ethnicity statistically significantly different from one another at the 5 percent level. ${ }^{63}$ Effects on prematurity are likewise of similar magnitude for women of different racial/ethnic backgrounds for both states. However, for California (but not for Texas), we reject the equality of the low birth weight estimates. The effect for black women is consistent with education improving wellbeing and is on the cusp of significance. However, the effect for white non-Hispanic women

\footnotetext{
${ }^{61}$ Angrist and Krueger (1991) similarly document much stronger effects of compulsory schooling for white men compared to black men, and Lleras-Muney (2005) echoes this conclusion for changes in child labor laws and compulsory schooling laws. Goldin and Katz (2003) argue that continuation schools, an important factor in the rise in educational attainment for 1910 to 1940, have similar effects for blacks and whites.

${ }^{62}$ Because of the smaller sample sizes underlying the estimates in this table, we use a slightly larger bandwidth of 70 days throughout. This is appropriate for a bandwidth selector of order $n^{-1 / 5}$ (cf., Pagan and Ullah 1999), since several of our estimates are based on 20 percent subsamples $\left(50 \times 0.2^{-1 / 5} \approx 70\right)$.

${ }^{63}$ Throughout the discussion of Table 5, we test restrictions using the objective function for the efficient minimum distance estimator, evaluated at the minimand. These test statistics may be calculated using the information in the table and are unreported.
} 
is of the opposite sign and statistically distinguishable from zero. This estimate could be consistent with some of the stress hypotheses discussed in the medical literature (e.g., Hedegaard, Henriksen, Sabroe and Secher 1993), and could be related to the effect of education on occupational stress. Moreover, while the Texas low birth weight effects are statistically similar across racial/ethnic groups, white non-Hispanic women in Texas also have effects that may be consistent with job stress, although the standard errors do not warrant strong interpretation.

As a second reason for differences across studies, if the relationship between schooling and infant health is non-linear, the estimated effect of education will depend on the level of education manipulated by the intervention. In the cross-section, there is evidence of such non-linearities, with the biggest health returns concentrated amongst the lowest-educated. ${ }^{64}$ As emphasized by Figure 3, school entry policies primarily affect the number of years of high school education. Other interventions in other settings could affect other educational margins, such as primary schooling or college.

Third, for different interventions, the effect of education may operate through different channels, potentially explaining differences in the effect of education for different groups. For example, individuals may learn in college about the health implications of smoking, in which case obtaining a college degree might reduce a woman's likelihood of smoking. If individuals do not learn about smoking while in high school, then obtaining a high school degree might not have as substantial an impact on smoking behavior. In this example, interventions targeting college would have larger direct/Grossman effects on infant health than would interventions targeting high school. This heterogeneity may likewise spill over to the indirect effects of education if different interventions affect differently the resources made available by virtue of education. For example, the mothers in Currie and Moretti's (2003) study are 24 to 45 years old and likely are old enough to have experienced the labor and mating market consequences of their education. Thus, for these women, the effect of

\footnotetext{
${ }^{64}$ This need not imply that the causal gradient is non-linear.
} 
education is plausibly a combination of both the direct/Grossman and the indirect effect. The mothers in our own study may be too young to have yet experienced the income effects of their education. In that case, our estimates might reflect only the direct/Grossman effect. ${ }^{65}$

This conclusion may be misleading, however, as our data do provide some suggestive evidence of income differences between women born before and after the school entry cutoff dates. For California, an extra year of education reduces the likelihood of public payment for delivery (e.g., Medicaid) and raises the likelihood of private payment (e.g., private insurance), leaving self-payment (i.e., out-of-pocket) unaffected (results available on request). In most cases, eligibility for public funding is dependent on income. This suggests that, already at motherhood, the women in our study are experiencing differences in income due to their education. Alternatively, they might anticipate future income differences and exert more effort in becoming eligible (e.g., completing paperwork). For Texas, an extra year of education lowers the likelihood that a woman receives prenatal care in a hospital and raises the likelihood that she receives care in a private clinic, leaving unchanged the likelihood of care in a public health clinic (results available upon request).

A fourth potential source of heterogeneity in the estimated effect of education relates to the persistence of the schooling differences induced by school entry policies. The women in our sample may return to school after childbearing, in which case a correct interpretation of our estimates would be the effect of transitory levels of schooling on infant health. Arguably the women in Currie and Moretti's (2003) sample have completed their schooling. To understand the dynamics of female schooling decisions following first births, we examined the patterns of school enrollment and school completion among the sample of women from the 1979 National Longitudinal Survey of Youth (NLSY79) (results not included). School enrollment rates in the post-birth period are strongly correlated with age at first birth. Women who have their first birth before age 18 are more likely to attend school subsequent to child-

\footnotetext{
${ }^{65}$ However, it is important to note that in the absence of borrowing constraints and in the presence of perfect foresight, these young mothers might correctly anticipate the labor and mating market consequences of their education and behave accordingly.
} 
bearing relative to women who delayed their childbearing. Over half of teenage mothers return to school but a smaller percentage of them actually finish more schooling. These school enrollment rates and school completion rates, however, drop precipitously at age 18 . This leads us to conclude that among mothers younger than 18, our estimates may be isolating the effect of education at motherhood rather than the effect of completed education and that among those $18-23$, the identified effect is the effect of completed education. ${ }^{66}$

To ascertain whether these two effects are substantially different, we stratify the sample based on two age groups: mothers less than 18 years old and mothers 18-23 years old (Table 5). As suggested by Figure 2, the education discontinuity is smaller for 18-23 year olds than for those below 18. However, for low birth weight and prematurity, the estimates are statistically indistinct. We interpret this pattern as suggestive evidence that both the direct/Grossman effect and the indirect effect are small for the women in our sample.

A final point of interpretation pertains to contrasting the impact of school entry policies with that of alternative policy measures. To fix ideas, consider the two broad types of policies that could increase years of schooling: (i) those affecting school exit decisions (e.g., raise the minimum dropout age) and (ii) those affecting school entrance decisions (e.g., lower the age at school entry). ${ }^{67}$ While both types of policies could equally raise educational attainment, each could have different effects on fertility behaviors and infant health outcomes. Envision a woman who desires to complete her schooling before starting her family and is constrained by compulsory schooling laws (i.e., she will drop out of school as soon as she lawfully can). Under the first type of intervention, an increase in the compulsory schooling age by one year will likely lead her to delay childbearing by one year. In that case, we would observe

\footnotetext{
${ }^{66}$ While the NLSY79 provides some useful insight, ultimately we would like to test whether there is a differential rate of subsequent enrollment between mothers born before and after the school entry cutoff date. Using an auxiliary Texas panel data where we can follow mothers across births, we can directly test for persistence in the first stage beyond the first birth. In particular, we test whether the discontinuity in education by mother's day of birth that we observe for first births persists for these same women who have second births. Our findings reveal that it does. The first stage for second-time mothers is roughly 70 percent the size of the first stage for the same mothers at the time of the first birth. Unfortunately, the sample size of this panel is too small to estimate the reduced-form and IV effects separately by parity for this sample.

${ }^{67}$ For studies in which schooling is measured not merely in years, additional interventions of interest include those aimed at increasing the quality of schooling, holding time spent in schooling constant.
} 
a simultaneous manipulation of education and age at motherhood, leading us to be unable to separately identify the effects of education from the effects of age at motherhood without additional instruments. ${ }^{68}$ On the other hand, suppose that the same woman is exposed to a policy change which lowers the age at which she enters school. As in the first case, she may have an increased level of acquired schooling. However, her age at motherhood will not be mechanically affected. Further, as argued in Section III, if age at motherhood does not depend on educational attainment, differences in starting age affect education but not maternal age. Thus, schooling interventions that affect school exit choices will have combined effects on educational attainment and age at motherhood, while policies that manipulate age at school entry may be less affected by such confounding. ${ }^{69}$

Moreover, because age at school entry type interventions occur early in a female's lifecycle before irreversible decisions are made (e.g., childbearing), the female is able to adapt along more dimensions because the change to her school optimization decision is fully anticipated. In contrast, an increase in the minimum dropout age is an unanticipated shock which may occur after a woman has made many of her decisions regarding her optimal fertility. For instance, a surprise change to the minimum dropout age from 17 to 18 cannot alter the pre17 sexual behavior of those aged 17 at the time of the change to the minimum dropout age. On the other hand, had the policy change been pre-announced, the same woman may have changed her pre-17 sexual behavior to reflect her knowledge of the effects of the policy upon her. In general, we would argue that interventions affecting school entry are more tightly linked to the theoretical models developed in the literature, for which anticipated lifetime income plays an important role (for a summary, see Hotz, Klerman and Willis 1997), than are interventions affecting school exit.

Despite the differences between our estimates and other quasi-experimental studies in this area, our results are consistent with much of the literature examining the effectiveness of teen

\footnotetext{
${ }^{68}$ Since such a policy mechanically affects fertility, it is difficult to relate fertility effects to the existing theoretical literature, which emphasizes behavioral relationships.

${ }^{69}$ The combined effect of age and education on infant health may nonetheless be of interest as a means of evaluating school exit policies.
} 
pregnancy prevention programs. Arguably, teenagers targeted in these interventions are more comparable to our sample than the Currie and Moretti (2003) sample. Several meta-analyses synthesizing the results from both randomized controlled trials and observational studies suggest that these interventions have a limited impact on adolescent behavior regarding sexual intercourse, birth control, and pregnancy (DiCenso, Guyatt, Willan and Griffith 2002, Bennett and Assefi 2005). ${ }^{70}$

\section{Conclusion}

We have argued that, for some women, education may play a more muted role in fertility and child investment decisions than suggested by the previous literature. Our evidence is based on comparisons of outcomes between women born just before and after the school entry date. Compared to women born just before the school entry date, women born just after the entry date (i) have substantially lower schooling, as expected, (ii) are equally likely to become mothers, (iii) give birth at similar ages, and (iv) give birth to similarly healthy infants. That we do not document differences in infant health is surprising, given the assortative mating results: school entry policies lead to economically important differences in the age and education of a woman's mate. These comparisons are credible to the extent that confounders are smooth in day of birth. On prior grounds we find it credible that two individuals born near in time are exchangeable. To substantiate this point, we have provided evidence that measured pre-determined characteristics are similar for women born just before and after the school entry date.

Our estimates are specific to the subpopulation of women whose education at motherhood

\footnotetext{
${ }^{70}$ Corcoran, Miller and Bultman (1997) conclude that there is some evidence of small effects of adolescent pregnancy prevention programs on teenage pregnancy. However, these results are driven by estimates from community-based programs rather than from school-based programs, which are more relevant for our study. Moreover, the observational studies included in the analysis are responsible for the statistically significant combined effect, and consistent with Guyatt, DiCenso, Farewell, Willan and Griffith (2000), the estimated effect size from observational studies greatly exceeds that from randomized controlled trials. It should be noted that in most of these evaluations, particularly the randomized controlled trials, the control group received some sexual education while the treatment group underwent more extensive training.
} 
is affected by school entry policies. These women may be negatively selected, for several reasons. First, their parents were willing to comply with school entry policies, as is more common among parents with low income. Second, school entry policies affect education at motherhood for those women giving birth at young ages with low education generally. Thus, these results may be difficult to generalize to other subpopulations. ${ }^{71}$

On the other hand, this may mean that our results are relevant for specific policies. The National Campaign to Prevent Teen Pregnancy, a non-profit and non-partisan initiative, emphasizes the importance of schooling in reducing rates of teenage pregnancy. Our results suggest that such emphasis may be misplaced. When policymakers envision expensive interventions to raise female education, they should think carefully of how they expect increases in education to improve well-being, particularly with teenagers.

Finally, these estimates directly address the fertility and infant health consequences of starting school early. Parents of children with birthdays near the school entry date may be interested in these findings, particularly if they view their child as at risk of dropping out of school. Moreover, there continues to be an active policy debate regarding the appropriate age at school entry, and several states have changed the school entry date to earlier in the year in order to raise the average age of kindergartners. Our results suggest that even if moving back the entry date does succeed in improving the preparedness of children for an increasingly intensive kindergarten curriculum, such a policy shift is not without costs and may create both winners and losers.

\section{References}

Ahn, Hyungtaik and James L. Powell, "Semiparametric Estimation of Censored Selection Models with a Nonparametric Selection Mechanism," Journal of Econometrics, July 1993, 58 (1-2), 3-29.

Aizenman, Nurith C., "Md. Moves Cutoff Date for Kindergartners; Concerns That Younger Students Can't Keep Up Prompt Gradual Shift to Sept. 1," Washington Post, May 22, 2002 .

\footnotetext{
${ }^{71}$ In addition, we have emphasized further features of our approach that problematize extrapolation to other contexts.
} 
Almond, Douglas, Kenneth Y. Chay, and David S. Lee, "The Costs of Low Birth Weight," Quarterly Journal of Economics, 2005, 120 (3), 1031-1083.

Andrews, Donald W.K., Marcelo J. Moreira, and James H. Stock, "Optimal Invariant Similar Tests for Instrumental Variables Regression," Econometrica, March 2006, 74 (3), 715-752.

Angrist, Joshua D. and Alan B. Krueger, "Does Compulsory School Attendance Affect Schooling and Earnings?," Quarterly Journal of Economics, November 1991, 106 (4), 979-1014.

and __ , "The Effect of Age at School Entry on Educational Attainment: An Application of Instrumental Variables with Moments from Two Samples," Journal of the American Statistical Association, June 1992, 87 (418), 328-336.

and Guido W. Imbens, "Two-Stage Least Squares Estimation of Average Causal Effects in Models with Variable Treatment Intensity," Journal of the American Statistical Association, June 1995, 90 (430), 431-442.

, Victor Chernozhukov, and Ivan Fernandez-Val, "Quantile Regression Under Misspecification with an Application to the U.S. Wage Structure," Econometrica, March 2006, 74 (2), 539-563.

Becker, Gary S., "An Economic Analysis of Fertility," in National Bureau of Economic Research, ed., Demographic and Economic Change in Developed Countries-A Conference of the Universities - National Bureau Committee for Economic Research, Princeton: Princeton University Press, 1960, pp. 209-240.

"A Theory of the Allocation of Time," Economic Journal, September 1965, 75 (299), $493-517$.

and H. Gregg Lewis, "On the Interaction Between the Quantity and Quality of Children," Journal of Political Economy, Part 2: New Economic Approaches to Fertility 1973, 81 (2), S279-S288.

Bedard, Kelly and Elizabeth Dhuey, "The Persistence of Early Childhood Maturity: International Evidence of Long-Run Age Effects," Quarterly Journal of Economics, November (forthcoming) 2006, 121 (4).

Behrman, Jere R. and Mark R. Rosenzweig, "Does Increasing Women's Schooling Raise the Schooling of the Next Generation?," American Economic Review, March 2002, 92 (1), $323-334$.

Bennett, Sylvana and Nassim Assefi, "School-Based Teenage Pregnancy Prevention Programs: A Systematic Review of Randomized Controlled Trials," Journal of Adolescent Health, 2005, 36, 72-81. 
Black, Sandra E., Paul J. Devereux, and Kjell G. Salvanes, "Fast Times at Ridgemont High? The Effect of Compulsory Schooling Laws on Teenage Births," NBER Working Paper \#10911, November 2004.

Bound, John, David A. Jaeger, and Regina M. Baker, "Problems with Instrumental Variables Estimation when the Correlation between the Instrument and the Endogenous Explanatory Variable Is Weak," Journal of the American Statistical Association, June 1995, 90 (430), 443-450.

Breierova, Lucia and Esther Duflo, "The Impact of Education on Fertility and Child Mortality: Do Fathers Really Matter Less Than Mothers?," NBER Working Paper \#10513, 2004 .

Card, David E., "The Causal Effect of Education on Earnings," in Orley Ashenfelter and David E. Card, eds., The Handbook of Labor Economics, Vol. 3A, Amsterdam: Elsevier, 1999.

Cascio, Elizabeth U. and Ethan B. Lewis, "Schooling and the AFQT: Evidence from School Entry Laws," Journal of Human Resources, Spring 2006, 41 (2), 294-318.

Cheng, Ming-Yen, Jianqing Fan, and James S. Marron, "On Automatic Boundary Corrections," The Annals of Statistics, August 1997, 25 (4), 1691-1708.

Chou, Shin-Yi, Jin-Tan Liu, Michael Grossman, and Theodore Joyce, "Parental Education and Child Health: Evidence from a Natural Experiment in Taiwan," 2003. Unpublished manuscript, City University of New York.

Corcoran, Jacqueline, Pamela O'Dell Miller, and Linda Bultman, "Effectiveness of Prevention Programs for Adolescent Pregnancy: A Meta-Analysis," Journal of Marriage and the Family, 1997, 59 (3), 551-567.

Currie, Janet and Enrico Moretti, "Mother's Education and the Intergenerational Transmission of Human Capital: Evidence From College Openings," Quarterly Journal of Economics, November 2003, 118 (4), 1495-1532.

Das, Mitali, Whitney Newey, and Francis Vella, "Nonparametric Estimation of Sample Selection Models," Review of Economic Studies, January 2003, 70 (1), 33-58.

Datar, Ashlesha, "Does Delaying Kindergarten Entrance Give Children a Head Start?," Economics of Education Review, February 2006, 25 (1), 43-62.

Davidson, Russell and James G. MacKinnon, Econometric Theory and Methods, New York: Oxford University Press, 2004.

de Walque, Damien, "Education, Information, and Smoking Decisions," July 2004. World Bank Policy Research Working Paper 3362.

DiCenso, Alba, Gordon H. Guyatt, Andrew Willan, and Lauren Griffith, "Interventions to Reduce Unintended Pregnancies among Adolescents: Systematic Review of Randomised Controlled Trials," British Medical Journal, 2002, 324, 1426-1435. 
DiNardo, John and Justin L. Tobias, "Nonparametric Density and Regression Estimation," Journal of Economic Perspectives, Fall 2001, 15 (4), 11-28.

Elder, Todd E. and Darren H. Lubotsky, "Kindergarten Entrance Age and Children's Achievement: The Impact of State Policies, Family Background, and Peers," April 2006. Unpublished manuscript, University of Illinois at Urbana-Champaign.

Fan, Jianqing and Irene Gijbels, Local Polynomial Modelling and Its Applications, New York: Chapman and Hall, 1996.

Friedman, Milton, A Theory of the Consumption Function, Princeton: Princeton University Press, 1957.

Glewwe, Paul, "Why Does Mother's Schooling Raise Child Health in Developing Countries? Evidence from Morocco," Journal of Human Resources, Winter 1999, 34 (1), 124-159.

Goldin, Claudia and Lawrence Katz, "Mass Secondary Schooling and the State: the Role of State Compulsion in the High School Movement," NBER Working Paper \# 10075, November 2003.

Gronau, Reuben, "Wage Comparisons-A Selectivity Bias," Journal of Political Economy, November-December 1974, 82 (6), 1119-1143.

Grossman, Michael, "On the Concept of Health Capital and the Demand for Health," Journal of Political Economy, March/April 1972, 80 (2), 223-255.

Guyatt, Gordon H., Alba DiCenso, Vern Farewell, Andrew Willan, and Lauren Griffith, "Randomized Trials versus Observational Studies in Adolescent Pregnancy Prevention," Journal of Clinical Epidemiology, 2000, 53, 167-174.

Hahn, Jinyong, Petra Todd, and Wilbert van der Klaauw, "Identification and Estimation of Treatment Effects with a Regression Discontinuity Design," Econometrica, February 2001, 69 (1), 201-209.

Hall, Peter, "Effect of Bias Estimation on Coverage Accuracy of Bootstrap Confidence Intervals for a Probability Density," The Annals of Statistics, June 1992, 20 (2), 675694.

Heckman, James J., "The Common Structure of Statistical Models of Truncation, Sample Selection, and Limited Dependent Variables and a Simple Estimator for Such Models," Annals of Economic and Social Measurement, 1976, 5 (4), 475-492.

"Sample Selection Bias as a Specification Error," Econometrica, January 1979, 47 (1), 153-162.

Hedegaard, Morten, Tine Brink Henriksen, Svend Sabroe, and Niels Jorgen Secher, "Psychological Distress in Pregnancy and Preterm Delivery," British Medical Journal, July 24, 1993, 307 (6898), 234-239. 
Horowitz, Joel L., "The Bootstrap," in James J. Heckman and Edward Leamer, eds., The Handbook of Econometrics, Vol. 5, New York: Elsevier, 2001, pp. 3159-3296.

Hotz, V. Joseph, Jacob Alex Klerman, and Robert J. Willis, "The Economics of Fertility in Developed Countries," in Mark R. Rosenzweig and Oded Stark, eds., The Handbook of Population and Family Economics, Vol. 1A, Amsterdam: Elsevier, 1997, pp. 275-347.

Kane, Thomas J., Cecilia Elena Rouse, and Douglas Staiger, "Estimating Returns to Schooling When Schooling is Mismeasured," NBER Working Paper \# 7235, July 1999.

Katz, Lawrence F., Jeffrey R. Kling, and Jeffrey B. Liebman, "Moving to Opportunity in Boston: Early Results of a Randomized Mobility Experiment," Quarterly Journal of Economics, May 2001, 116 (2), 607-654.

Kenkel, Donald S., "Health Behavior, Health Knowledge, and Schooling," Journal of Political Economy, April 1991, 99 (2), 287-305.

Lee, David S., "Training, Wages, and Sample Selection," October 2005. Unpublished manuscript, University of California, Berkeley.

and David E. Card, "Regression Discontinuity Inference with Specification Error," February 2006. Unpublished manuscript, University of California, Berkeley.

and Justin McCrary, "Crime, Punishment, and Myopia," NBER Working Paper \# 11491, July 2005.

Leon, Alexis, "The Effect of Education on Fertility: Evidence From Compulsory Schooling Laws," 2004. Unpublished manuscript, University of Pittsburgh.

Lleras-Muney, Adriana, "Were Comuplsory Attendance and Child Labor Laws Effective? An Analysis From 1915 to 1939," Journal of Law and Economics, October 2002, 45, $401-435$.

, "The Relationship Between Education and Adult Mortality in the United States," Review of Economic Studies, January 2005, 72 (1), 189-221.

Manski, Charles F., "Identification of Endogenous Social Effects: The Reflection Problem," Review of Economic Studies, 1993, 60 (3), 531-542.

, Identification Problems in the Social Sciences, Cambridge, MA: Harvard University Press, 1995.

"Economic Analysis of Social Interactions," Journal of Economic Perspectives, 2000, $14(3), 115-136$.

Michael, Robert T., "Education and the Derived Demand for Children," Journal of Political Economy, Part 2: New Economic Approaches to Fertility 1973, 81 (2), S128-S164. 
Mincer, Jacob, "Market Prices, Opportunity Costs, and Income Effects," in C. Christ, ed., Measurement in Economics: Studies in Mathematical Economics and Econometrics in Memory of Yehuda Grunfeld, Stanford: Stanford University Press, 1963.

Moreira, Marcelo J., "A Conditional Likelihood Ratio Test for Structural Models," Econometrica, July 2003, 71 (4), 1027-1048.

Newey, Whitney K. and Daniel L. McFadden, "Large Sample Estimation and Hypothesis Testing," in Robert F. Engle and Daniel McFadden, eds., Handbook of Econometrics, Vol. 4, New York: North-Holland, 1994, pp. 2111-2245.

Oreopoulos, Philip, Marianne E. Page, and Ann Huff Stevens, "The Intergenerational Effects of Compulsory Schooling," August 2005. Unpublished manuscript, University of California, Davis.

Pagan, Adrian and Aman Ullah, Nonparametric Econometrics, New York: Cambridge University Press, 1999.

Porter, Jack, "Estimation in the Regression Discontinuity Model," 2003. Unpublished manuscript, Harvard University.

Robinson, P.M., "Root-N-Consistent Semiparametric Regression," Econometrica, July 1988, $56(4), 931-954$.

Rosenzweig, Mark R. and Kenneth I. Wolpin, "Testing the Quantity-Quality Fertility Model: The Use of Twins as a Natural Experiment," Econometrica, January 1980, 48 (1), 227 240 .

and T. Paul Schultz, "Schooling, Information and Nonmarket Productivity: Contraceptive Use and Its Effectiveness," International Economic Review, May 1989, 30 (2), $457-477$.

Royer, Heather, "What All Women (and Some Men) Want to Know: Does Maternal Age Affect Infant Health?," University of California, Berkeley, Center for Labor Economics Working Paper \# 68, 2004.

Staiger, Douglas and James Stock, "Instrumental Variables Regression with Weak Instruments," Econometrica, May 1997, 65 (3), 557-586.

Stipek, Deborah, "At What Age Should Children Enter Kindergarten? A Question for Policy Makers and Parents," Social Policy Report, 2002, 16 (2), 3-16.

Strauss, John and Duncan Thomas, "Human Resources: Empirical Modeling of Household and Family Decisions," in J. Behrman and T.N. Srinivasan, eds., The Handbook of Development Economics, Vol. 3A, Amsterdam: Elsevier, 1995.

Thomas, Duncan, John Strauss, and Maria-Helena Henriques, "How Does Mother's Education Affect Child Height?," Journal of Human Resources, Spring 1991, 26 (2), 183-211. 
White, Halbert, "A Heteroskedasticity-Consistent Covariance Matrix Estimator and a Direct Test for Heteroskedasticity," Econometrica, 1980, 48 (4), 817-838.

Willis, Robert J., "A New Approach to the Economic Theory of Fertility," Journal of Political Economy, Part 2: New Economic Approaches to Fertility 1973, 81 (2), S14S64.

Wolfe, Barbara L. and Jere R. Behrman, "Women's Schooling and Children Health: Are the Effects Robust with Adult Sibling Control for the Women's Childhood Background?," Journal of Health Economics, September 1987, 6 (3), 239-254.

Wolpin, Kenneth I., "Determinants and Consequences of the Mortality and Health of Infants and Children," in Mark R. Rosenzweig and Oded Stark, eds., The Handbook of Population and Family Economics, Vol. 1A, Amsterdam: Elsevier, 1997, pp. pp. 483556.

Wooldridge, Jeffrey M., "Cluster-Sample Methods in Applied Econometrics," American Economic Review, May 2003, 93 (2), 133-138.

Yatchew, Adonis, "An Elementary Estimator of the Partial Linear Model," Economics Letters, December 1997, 57 (2), 135-143. 


\title{
Figure 1. Education at Motherhood, by Day of Birth: Native First-Time Mothers 23 Years Old and Younger
}

\author{
A. California
}

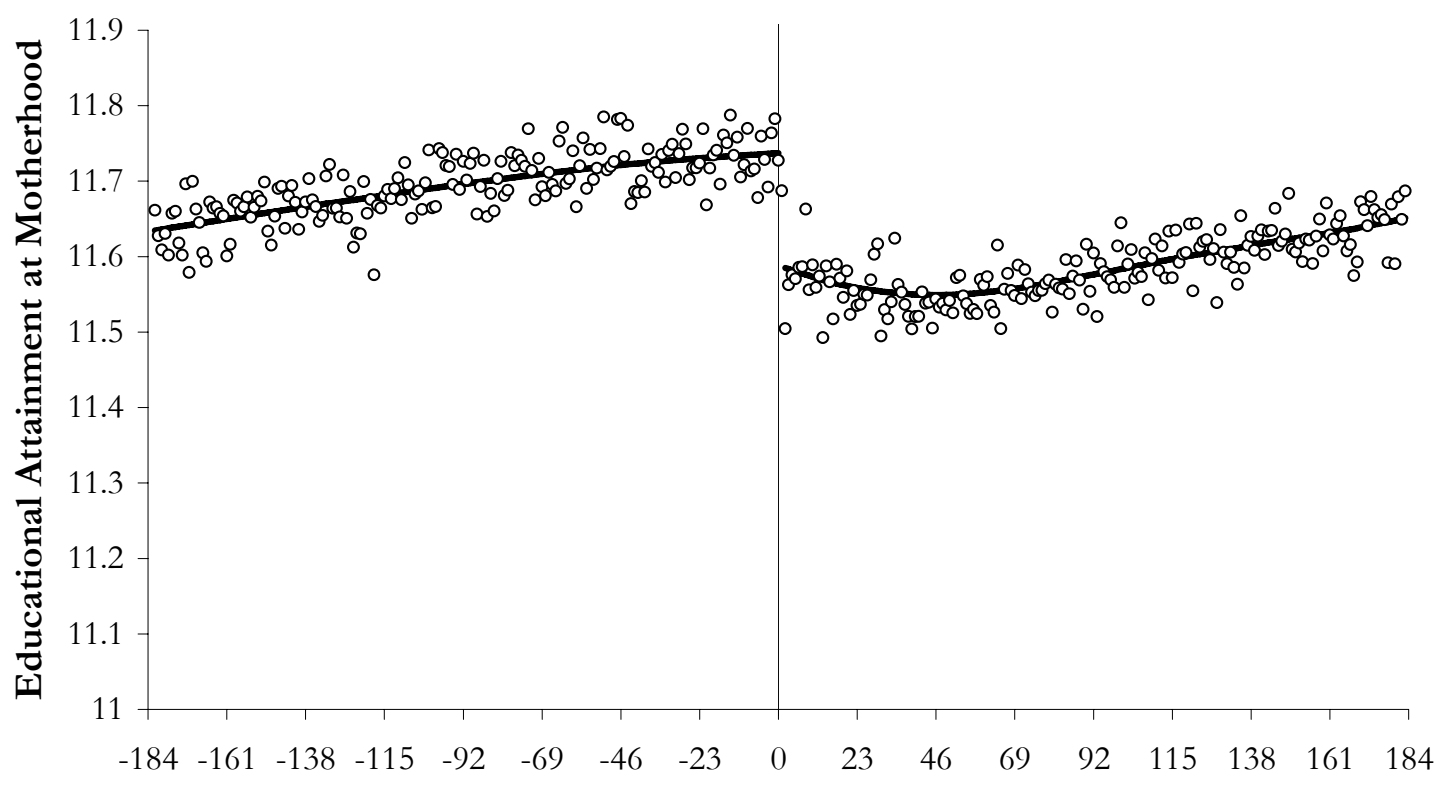

Day of Birth Relative to December 1

B. Texas

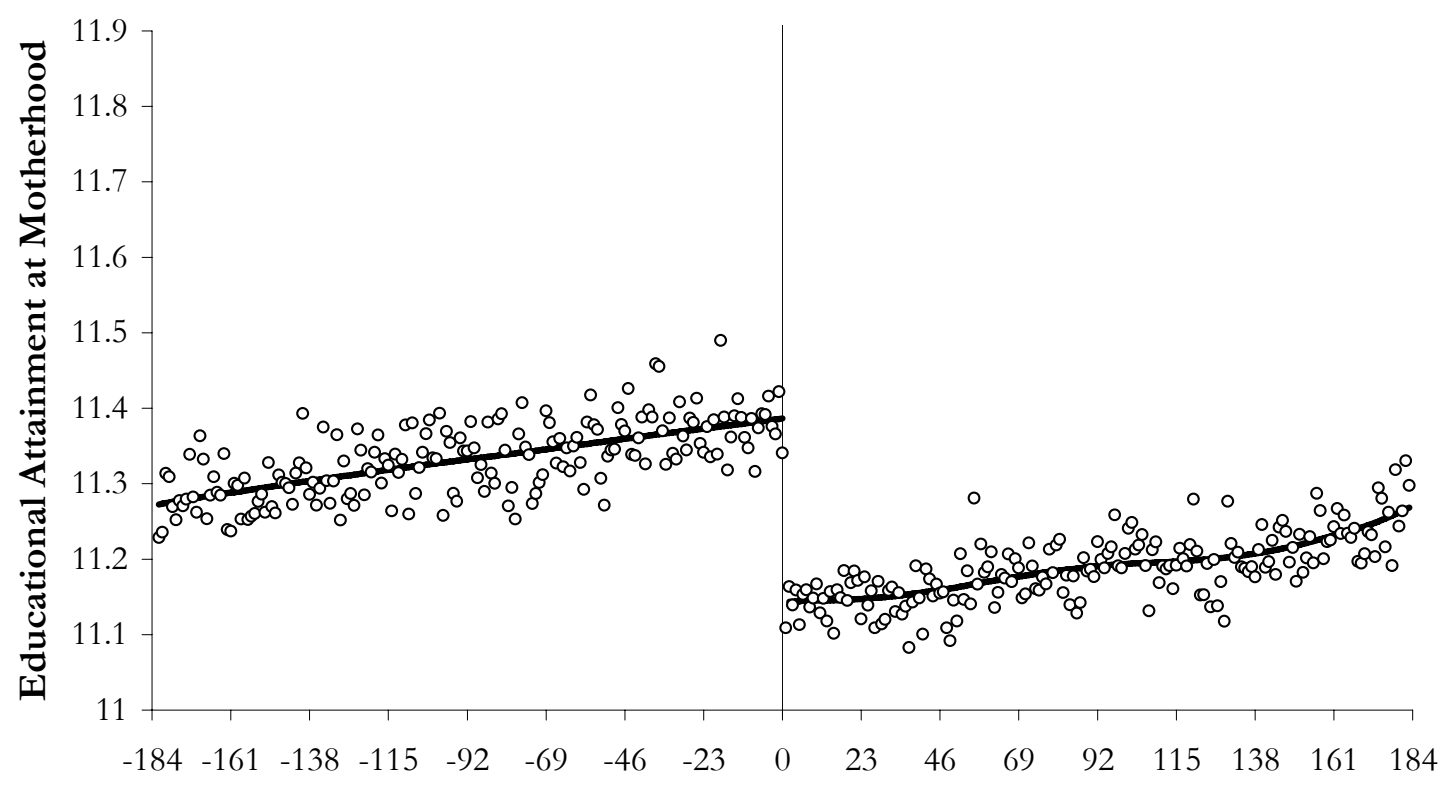

Day of Birth Relative to September 1 


\section{Figure 2. Education Discontinuities, by Age: Native First-Time Mothers}

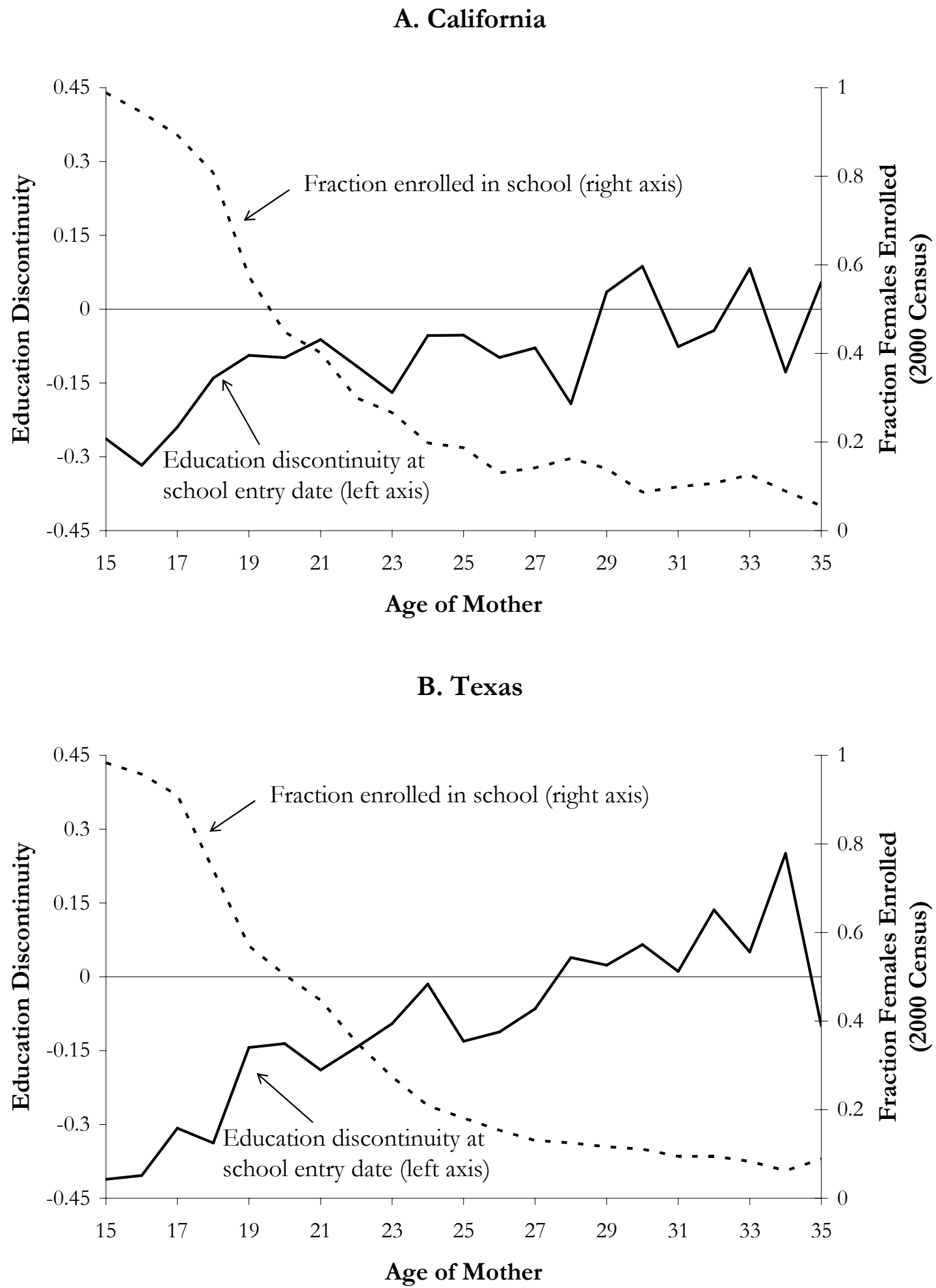


Figure 3. Distribution of Female Education Effects

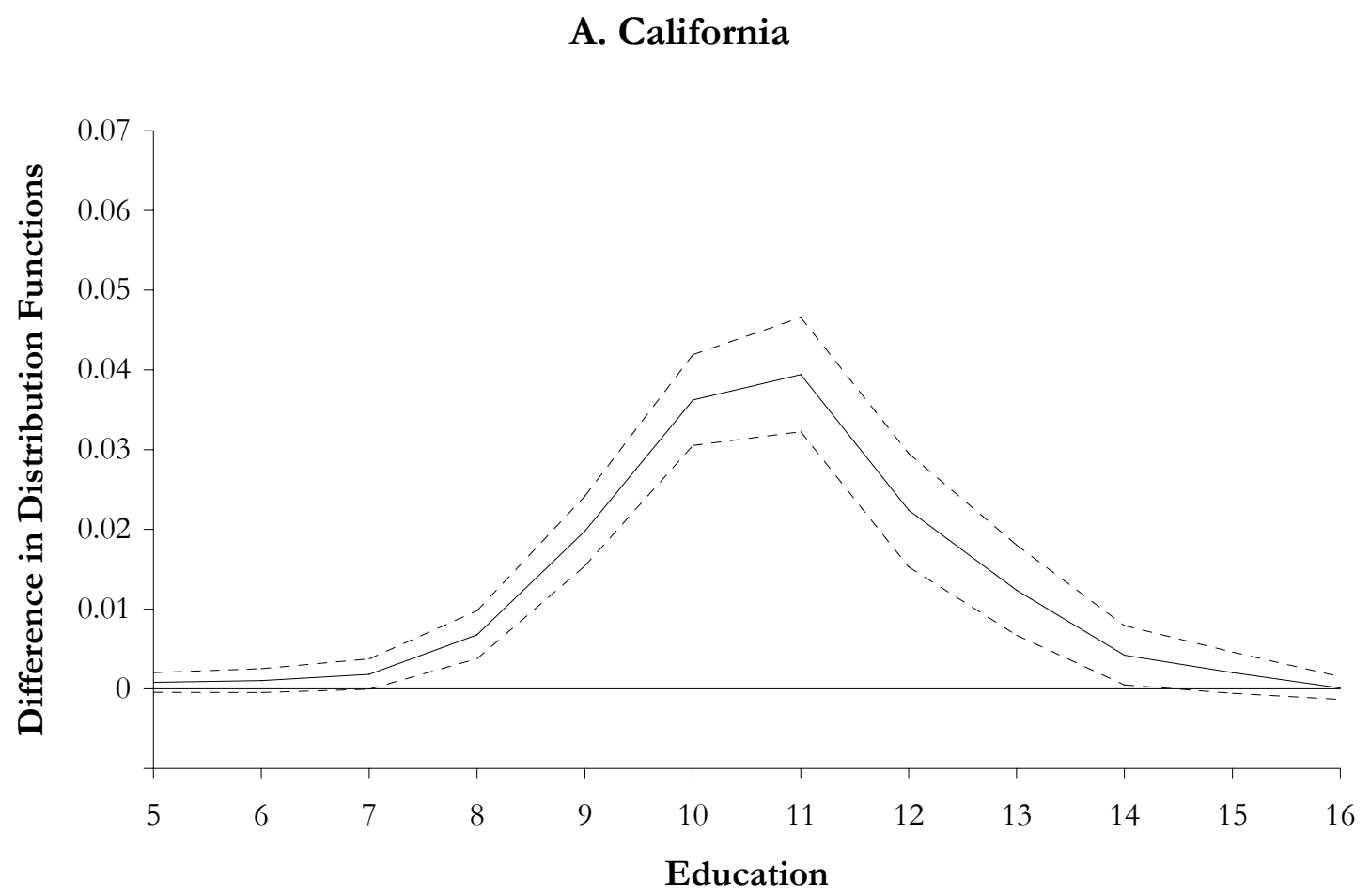

B. Texas

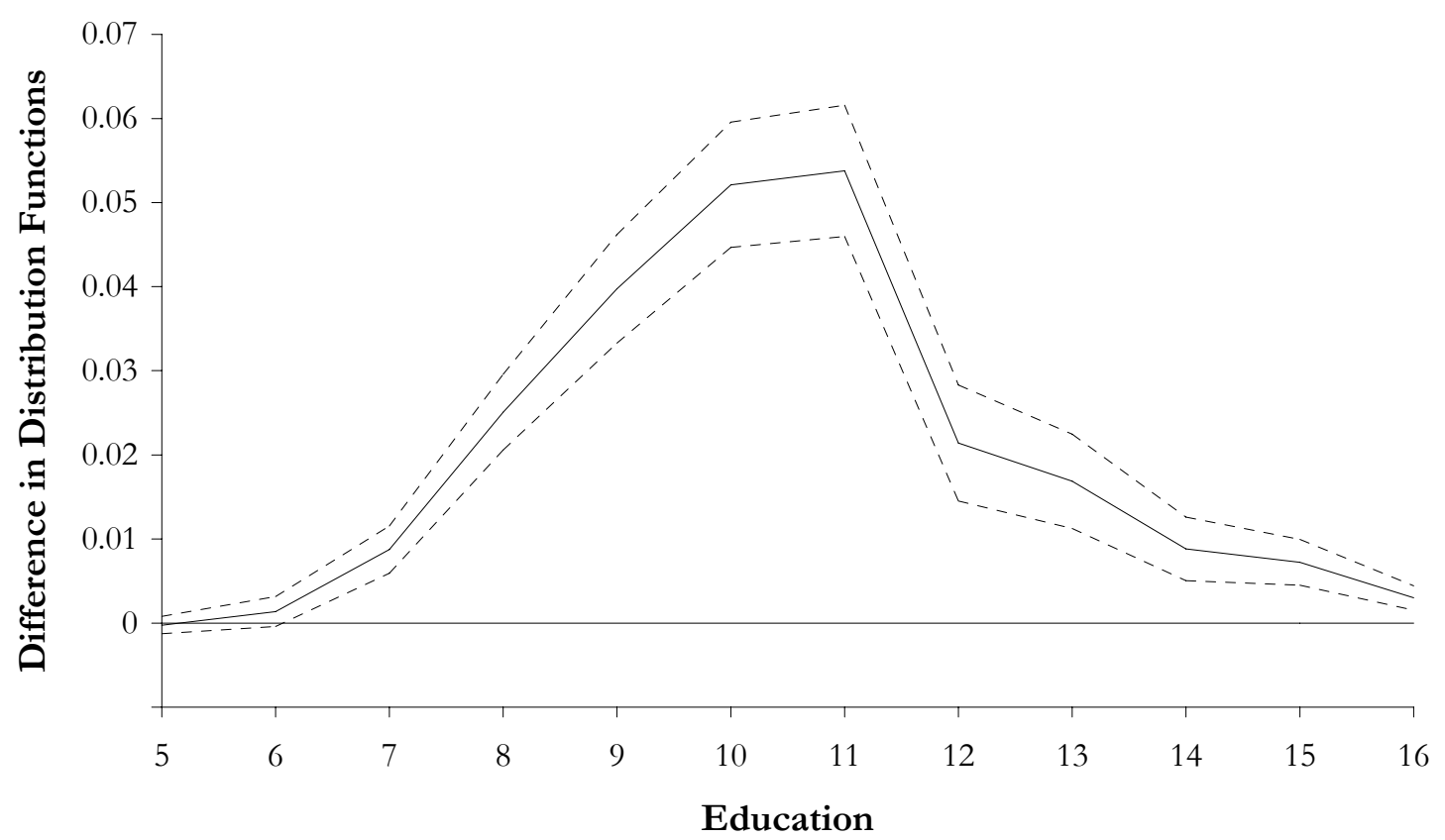




\section{Figure 4. Probability of Motherhood, by Day of Birth: Native Mothers}

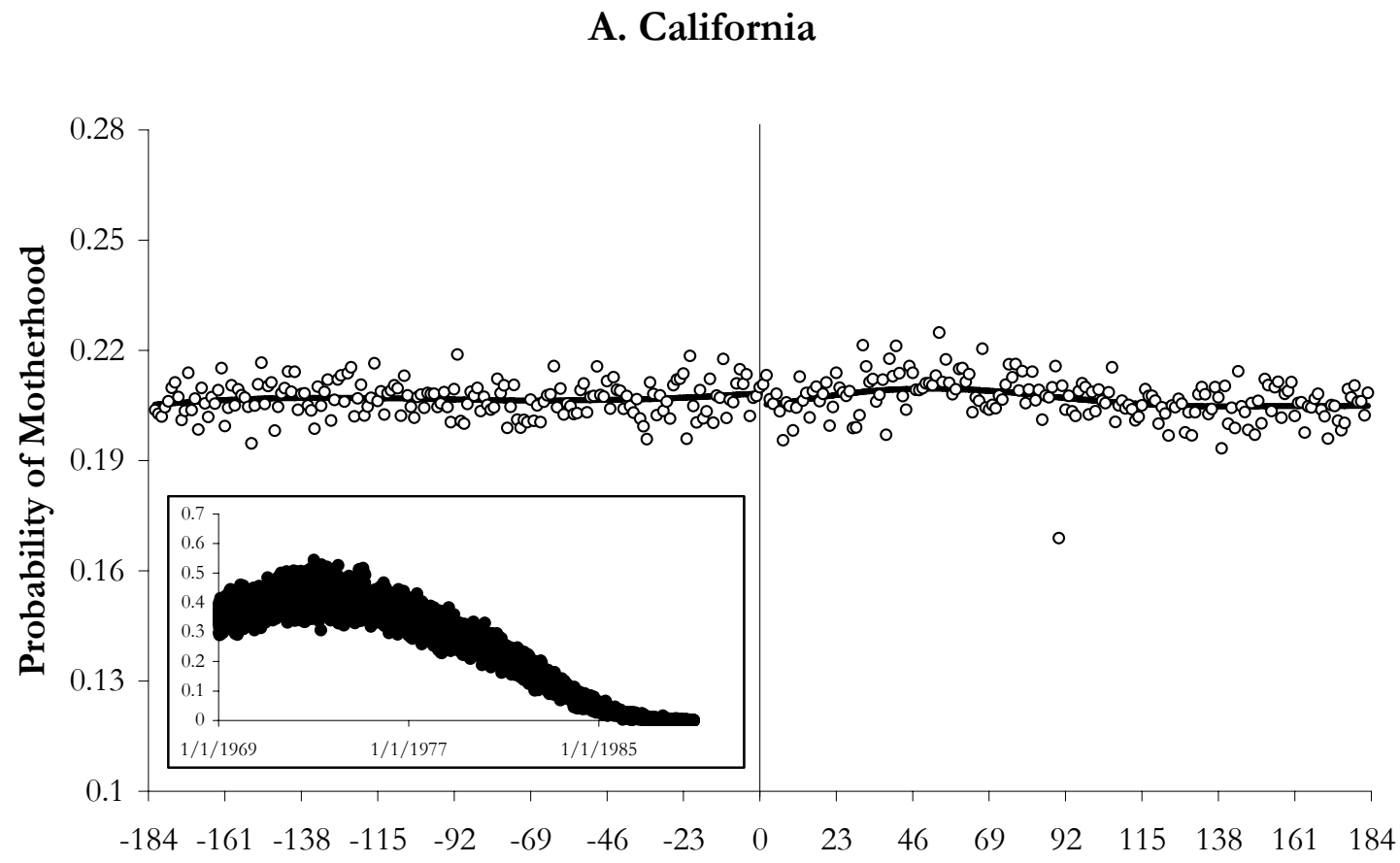

Day of Birth Relative to December 1

\section{B. Texas}

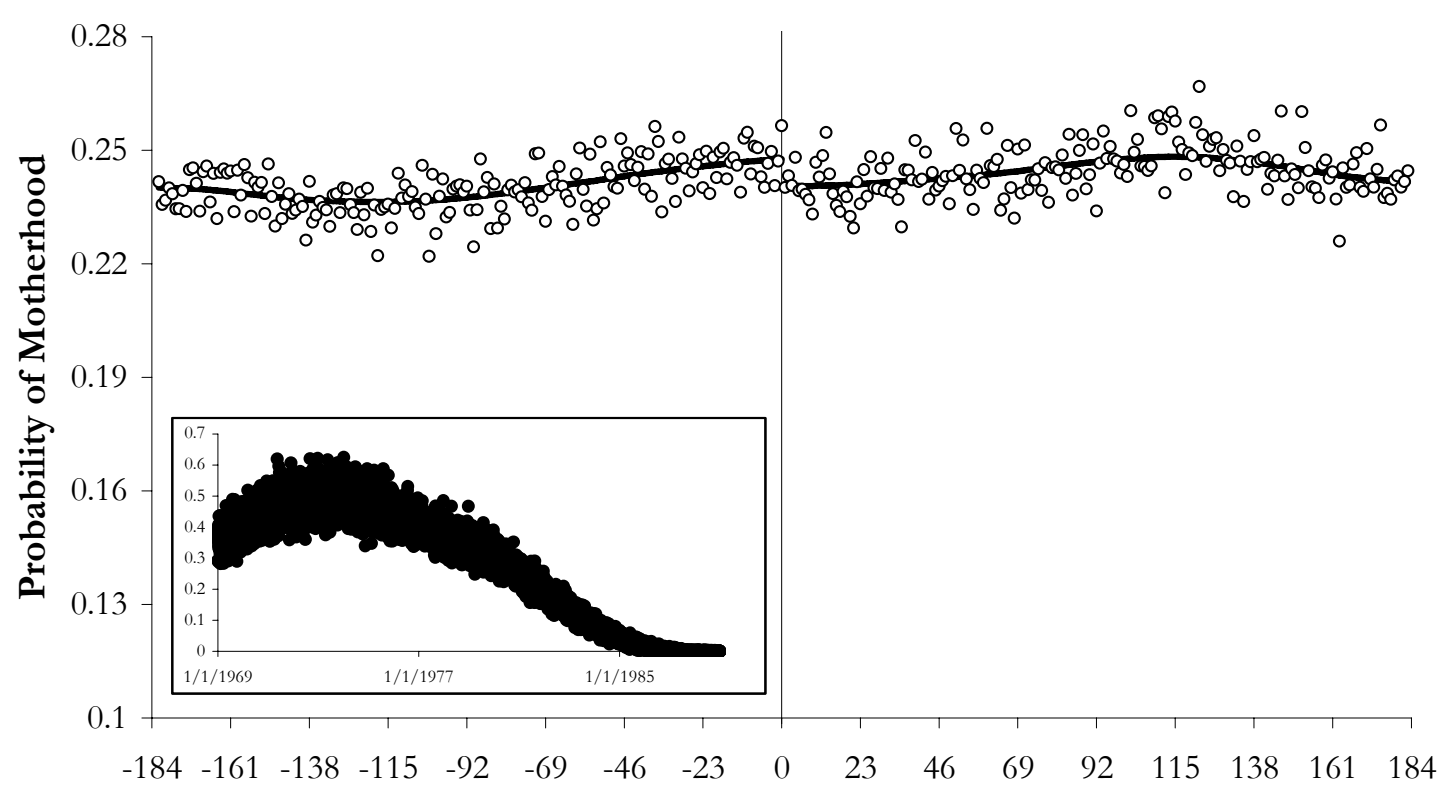

Day of Birth Relative to September 1 


\section{Figure 5. Maternal Age, by Day of Birth: \\ Native First-Time Mothers}

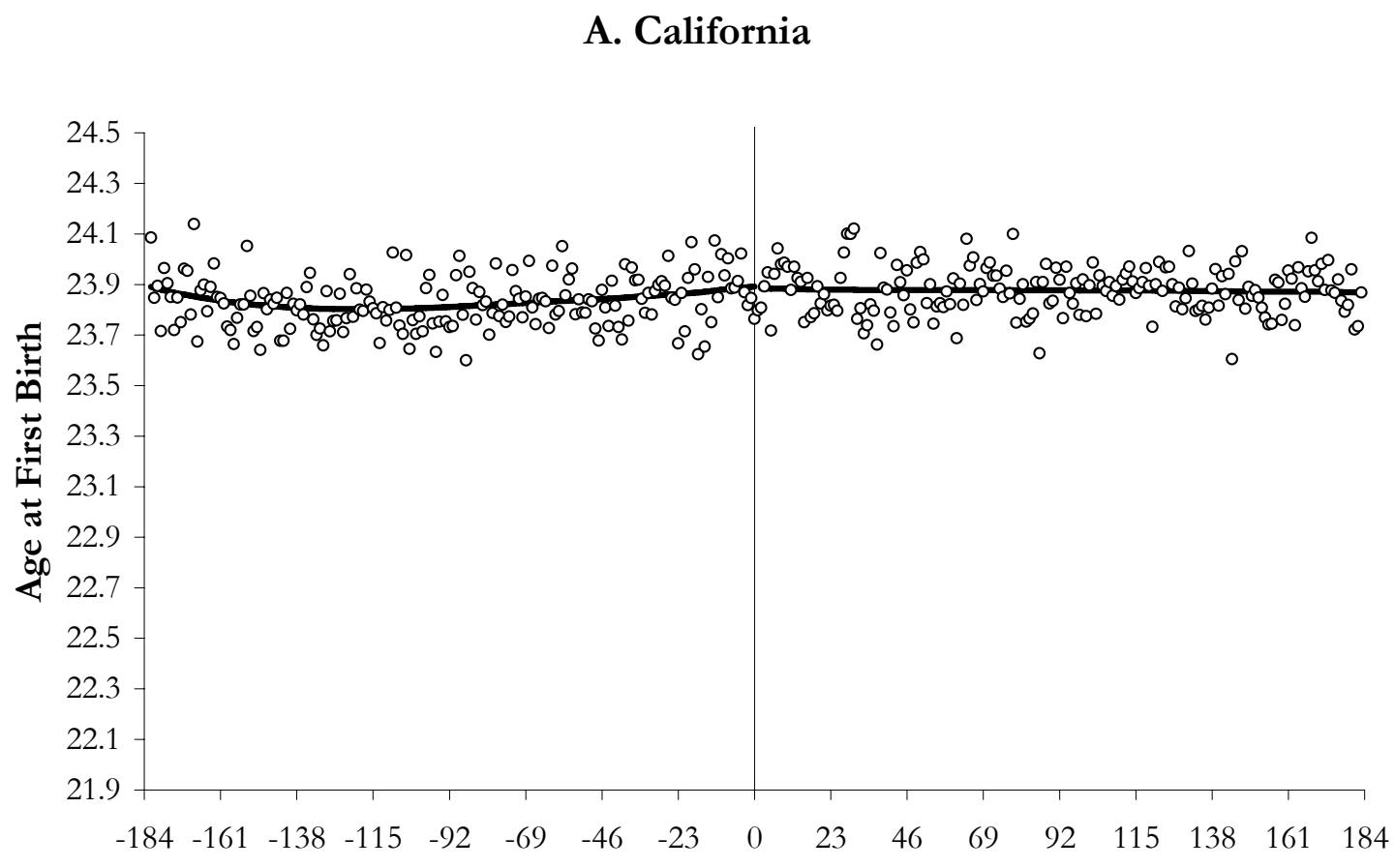

Day of Birth Relative to December 1

B. Texas

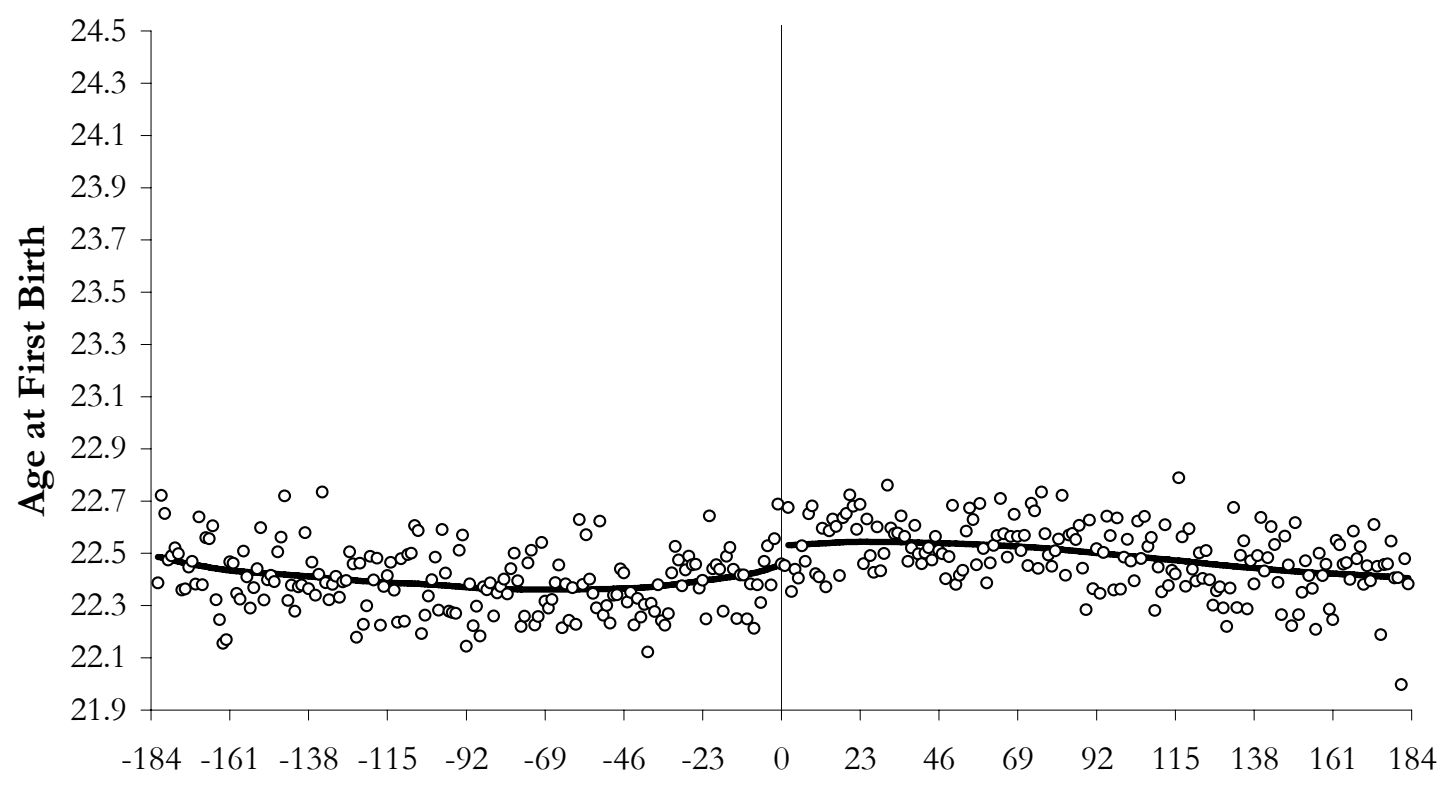

Day of Birth Relative to September 1 


\title{
Figure 6. Incidence of Low Birthweight, by Day of Birth: Native First-Time Mothers 23 Years and Younger
}

\author{
A. California
}

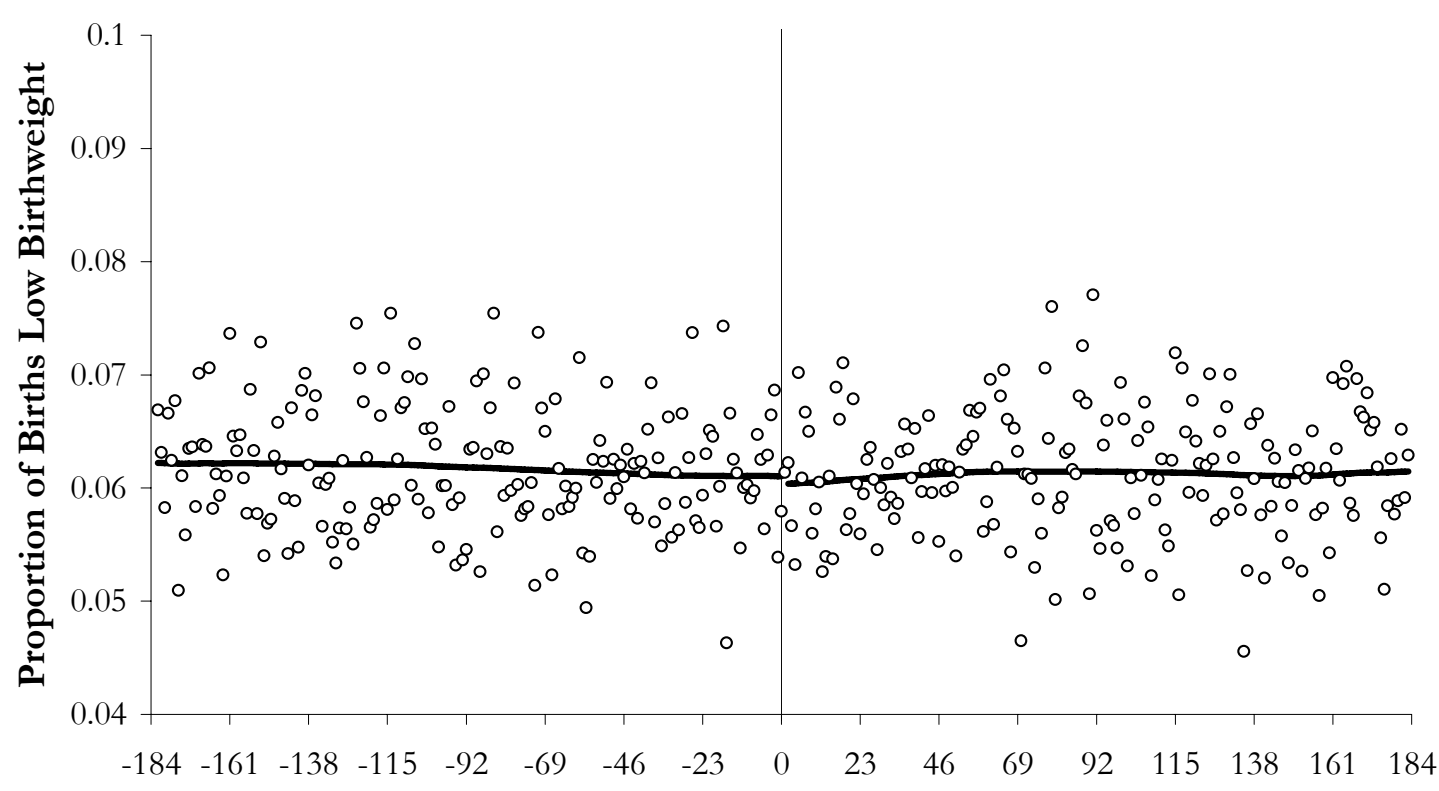

Day of Birth Relative to December 1

B. Texas

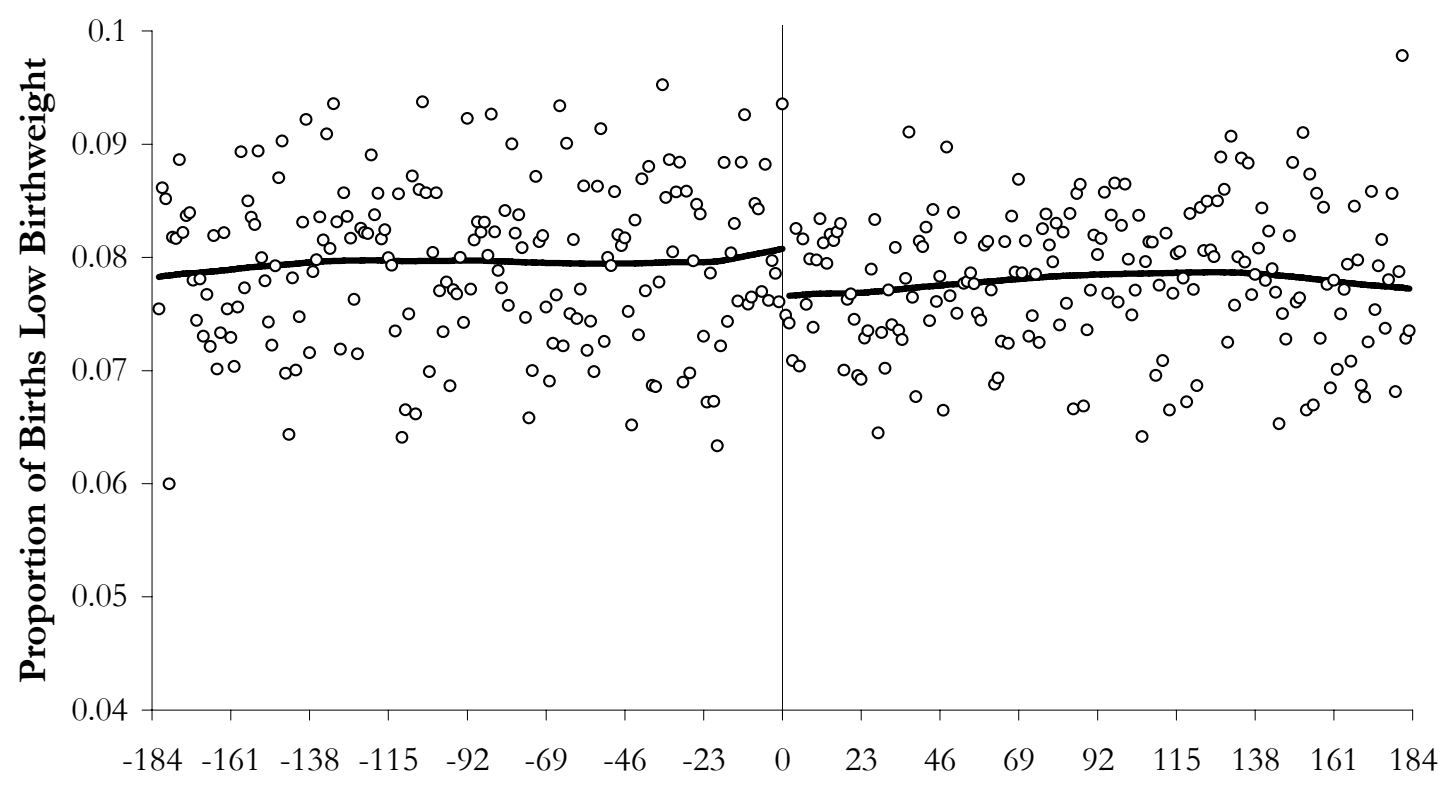

Day of Birth Relative to September 1 
Figure 7. Incidence of Prematurity, by Day of Birth: Native First-Time Mothers 23 Years and Younger

\author{
A. California
}

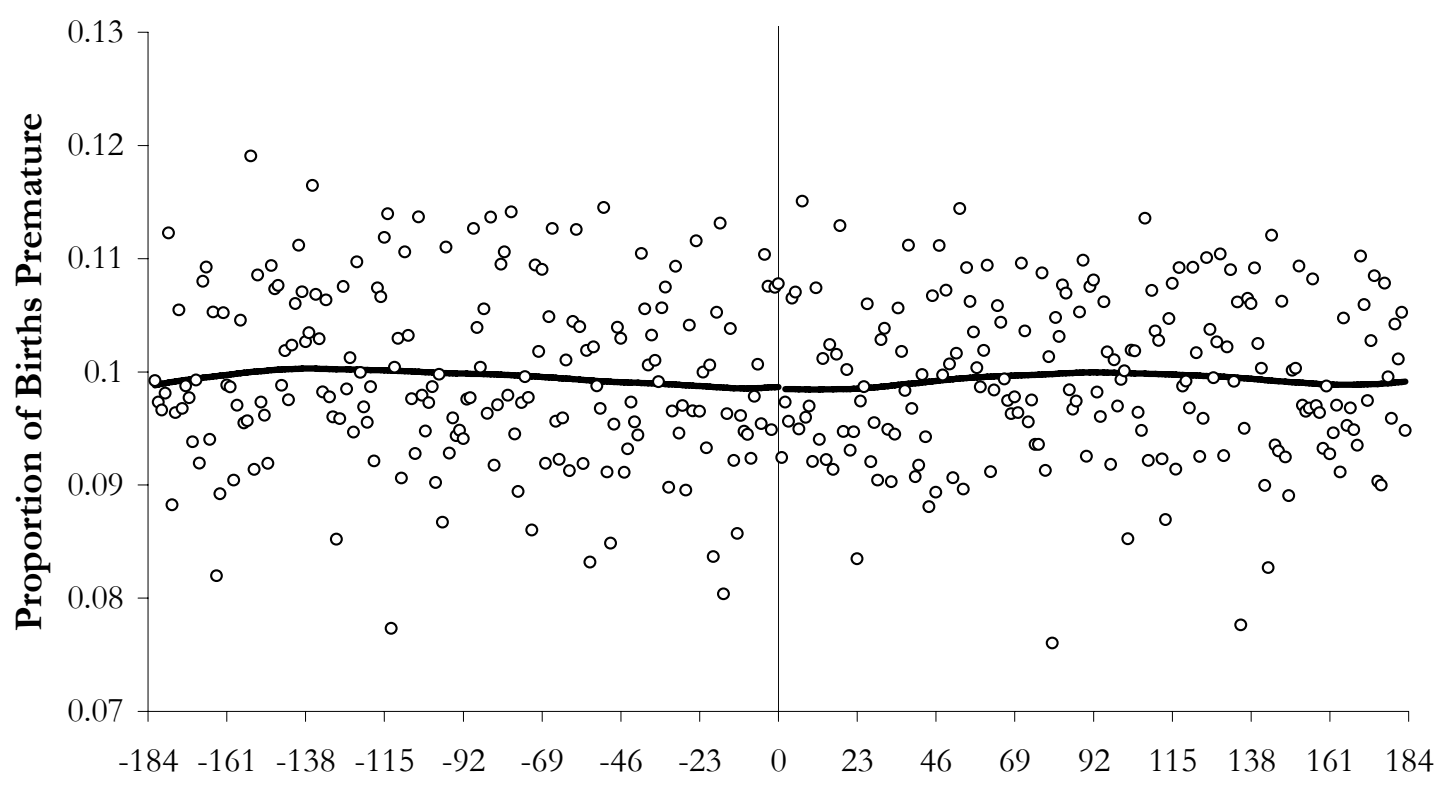

Day of Birth Relative to December 1

B. Texas

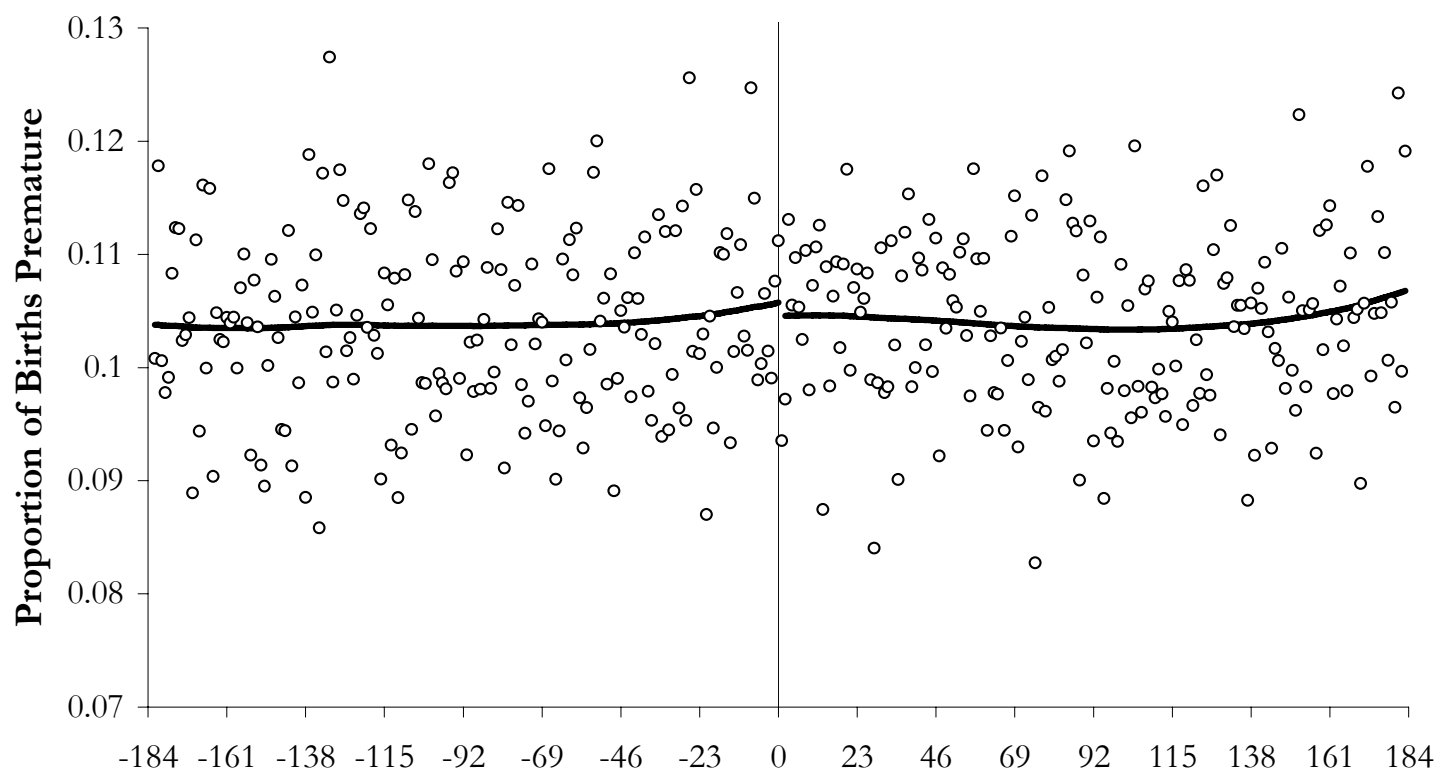

Day of Birth Relative to September 1 


\section{Table 1. Descriptive Statistics}

\begin{tabular}{|c|c|c|c|c|c|c|}
\hline & \multicolumn{3}{|c|}{ California (1989-2002) } & \multicolumn{3}{|c|}{ Texas (1989-2001) } \\
\hline & $\begin{array}{c}\text { All } \\
\text { Mothers }\end{array}$ & $\begin{array}{l}\text { First-Time } \\
\text { Mothers } \\
\end{array}$ & $\begin{array}{c}\text { First-Time } \\
\text { Native } \\
\text { Mothers } \\
\text { Under } 24 \\
\end{array}$ & $\begin{array}{c}\text { All } \\
\text { Mothers } \\
\end{array}$ & $\begin{array}{l}\text { First-Time } \\
\text { Mothers } \\
\end{array}$ & $\begin{array}{c}\text { First-Time } \\
\text { Native } \\
\text { Mothers } \\
\text { Under } 24 \\
\end{array}$ \\
\hline \% Mothers White Non-Hispanic & 36.09 & 39.15 & 38.71 & 42.96 & 45.22 & 39.78 \\
\hline \% Mothers White Hispanic & 45.25 & 41.26 & 43.64 & 41.90 & 39.47 & 40.66 \\
\hline$\%$ Mothers Black & 7.19 & 6.81 & 13.88 & 12.32 & 12.12 & 19.25 \\
\hline$\%$ Mothers Asian & 10.70 & 12.07 & 2.49 & 2.56 & 2.95 & 0.14 \\
\hline$\%$ Mothers Other & 0.79 & 0.72 & 1.29 & 0.27 & 0.26 & 0.20 \\
\hline Mother's education (years) & $\begin{array}{l}11.83 \\
{[3.51]}\end{array}$ & $\begin{array}{l}12.37 \\
{[3.20]}\end{array}$ & $\begin{array}{l}11.64 \\
{[1.69]}\end{array}$ & $\begin{array}{l}11.93 \\
{[3.06]}\end{array}$ & $\begin{array}{l}12.19 \\
{[2.93]}\end{array}$ & $\begin{array}{l}11.26 \\
{[1.86]}\end{array}$ \\
\hline Mother's age (years) & $\begin{array}{l}27.19 \\
{[6.17]}\end{array}$ & $\begin{array}{l}24.79 \\
{[6.09]}\end{array}$ & $\begin{array}{l}19.17 \\
{[2.31]}\end{array}$ & $\begin{array}{l}25.86 \\
{[5.98]}\end{array}$ & $\begin{array}{l}23.44 \\
{[5.66]}\end{array}$ & $\begin{array}{l}19.01 \\
{[2.32]}\end{array}$ \\
\hline$\%$ Low birth weight (<2500 grams) & 4.92 & 5.82 & 6.15 & 5.90 & 7.01 & 7.88 \\
\hline$\%$ Premature ( $<37$ weeks of gestation) & 9.25 & 9.16 & 9.95 & 9.00 & 9.13 & 10.39 \\
\hline $\begin{array}{l}\text { Infant mortality rate (deaths before } 1 \\
\text { year/1000 births) }\end{array}$ & NA & NA & NA & 5.71 & 5.70 & 6.70 \\
\hline$\%$ Mothers smoking during pregnancy & 2.03 & 1.58 & 2.90 & 7.80 & 6.33 & 8.48 \\
\hline$\%$ Mothers drinking during pregnancy & $\mathrm{NA}$ & NA & $\mathrm{NA}$ & 1.18 & 1.03 & 0.97 \\
\hline$\%$ Mothers with STDs & 1.34 & 1.52 & 1.68 & 2.24 & 2.60 & 3.81 \\
\hline$\%$ Mothers with prenatal care & 98.84 & 99.06 & 99.06 & 97.37 & 97.83 & 98.02 \\
\hline$\%$ Prenatal care began in 1 st trimester & 79.04 & 81.06 & 74.17 & 75.01 & 76.60 & 69.14 \\
\hline Number of prenatal care visits & $\begin{array}{l}11.39 \\
{[4.13]}\end{array}$ & $\begin{array}{l}11.75 \\
{[4.08]}\end{array}$ & $\begin{array}{l}11.41 \\
{[4.08]}\end{array}$ & $\begin{array}{l}10.91 \\
{[4.51]}\end{array}$ & $\begin{array}{l}11.21 \\
{[4.46]}\end{array}$ & $\begin{array}{l}10.80 \\
{[4.36]}\end{array}$ \\
\hline$\%$ Father present & 90.97 & 89.42 & 84.14 & 84.03 & 80.44 & 69.27 \\
\hline Father's age (years) & $\begin{array}{l}30.00 \\
{[6.97]}\end{array}$ & $\begin{array}{l}27.85 \\
{[6.94]}\end{array}$ & $\begin{array}{l}22.16 \\
{[4.18]}\end{array}$ & $\begin{array}{l}29.05 \\
{[6.71]}\end{array}$ & $\begin{array}{r}26.81 \\
{[6.5]}\end{array}$ & $\begin{array}{l}22.16 \\
{[4.18]}\end{array}$ \\
\hline Father's education (years) & $\begin{array}{l}11.89 \\
{[3.82]}\end{array}$ & $\begin{array}{l}12.30 \\
{[3.66]}\end{array}$ & $\begin{array}{l}11.51 \\
{[2.72]}\end{array}$ & $\begin{array}{l}12.32 \\
{[3.21]}\end{array}$ & $\begin{array}{l}12.60 \\
{[2.99]}\end{array}$ & $\begin{array}{l}11.69 \\
{[1.96]}\end{array}$ \\
\hline$\%$ Having first birth & 39.57 & 100.00 & 100.00 & 40.91 & 100.00 & 100.00 \\
\hline Observations & $7,515,248$ & $2,973,566$ & 697,572 & $4,003,275$ & $1,637,607$ & 564,217 \\
\hline
\end{tabular}

Notes: Mothers with missing education, parity, or birth date values or non-singleton births are excluded. The native subsample includes only mothers born in that state. Father's presence is measured by the presence of his educational attainment and birthdate on the birth certificate. Standard deviations in brackets. 


\section{Table 2. Effects of School Entry Policies: First-Stage and Reduced-Form Estimates}

\begin{tabular}{|c|c|c|}
\hline \multicolumn{3}{|c|}{ California } \\
\hline \multicolumn{3}{|c|}{ Maternal Characteristics } \\
\hline Mother's & Probability of & Mother's \\
\hline Education & Motherhood & Age \\
\hline-0.1499 & -0.0036 & 0.0052 \\
\hline$(0.0201)$ & $(0.0050)$ & $(0.0421)$ \\
\hline \multicolumn{3}{|c|}{ Birth Outcomes } \\
\hline Low & & Infant \\
\hline birthweight & Prematurity & Death \\
\hline-0.0003 & -0.0000 & NA \\
\hline$(0.0022)$ & $(0.0031)$ & \\
\hline
\end{tabular}

Risky Maternal Behaviors

\begin{tabular}{|c|c|c|}
\hline $\begin{array}{l}\text { Mother } \\
\text { Smokes }\end{array}$ & $\begin{array}{l}\text { Mother } \\
\text { Drinks }\end{array}$ & STDs \\
\hline $\begin{array}{c}0.0034 \\
(0.0013)\end{array}$ & NA & $\begin{array}{c}0.0019 \\
(0.0011)\end{array}$ \\
\hline
\end{tabular}

Prenatal Care

\begin{tabular}{|c|c|c|}
\hline Any Care & $\begin{array}{c}\text { Care in First } \\
\text { Trimester }\end{array}$ & $\begin{array}{c}\text { Number of } \\
\text { Visits }\end{array}$ \\
\hline 0.0000 & -0.0025 & -0.0169 \\
\hline$(0.0010)$ & $(0.0055)$ & $(0.0407)$ \\
\hline
\end{tabular}

Paternal Characteristics

\begin{tabular}{|c|c|c|}
\hline $\begin{array}{l}\text { Father } \\
\text { Present }\end{array}$ & Father's Age & $\begin{array}{c}\text { Father's } \\
\text { Education }\end{array}$ \\
\hline 0.0003 & -0.1464 & -0.1072 \\
\hline$(0.0039)$ & $(0.0302)$ & $(0.0235)$ \\
\hline
\end{tabular}

Texas

\begin{tabular}{|c|c|c|}
\hline \multicolumn{3}{|c|}{ Maternal Characteristics } \\
\hline Mother's & Probability of & Mother's \\
\hline Education & Motherhood & Age \\
\hline-0.2347 & -0.0067 & 0.0481 \\
\hline$(0.0119)$ & $(0.0034)$ & $(0.0522)$ \\
\hline
\end{tabular}

\section{Birth Outcomes}

\begin{tabular}{|c|c|c|}
\hline $\begin{array}{l}\text { Low } \\
\text { birthweight }\end{array}$ & Prematurity & $\begin{array}{l}\text { Infant } \\
\text { Death }\end{array}$ \\
\hline $\begin{array}{l}-0.0043 \\
(0.0025)\end{array}$ & $\begin{array}{l}-0.0018 \\
(0.0031)\end{array}$ & $\begin{array}{c}0.0013 \\
(0.0010)\end{array}$ \\
\hline
\end{tabular}

Risky Maternal Behaviors

\begin{tabular}{|c|c|c|}
\hline $\begin{array}{l}\text { Mother } \\
\text { Smokes }\end{array}$ & $\begin{array}{l}\text { Mother } \\
\text { Drinks }\end{array}$ & STDs \\
\hline $\begin{array}{l}-0.0012 \\
(0.0030)\end{array}$ & $\begin{array}{l}-0.0021 \\
(0.0009)\end{array}$ & $\begin{array}{c}0.0007 \\
(0.0022)\end{array}$ \\
\hline
\end{tabular}

\begin{tabular}{|c|c|c|}
\hline \multicolumn{3}{|c|}{ Prenatal Care } \\
\hline Any Care & $\begin{array}{c}\text { Care in First } \\
\text { Trimester }\end{array}$ & $\begin{array}{c}\text { Number of } \\
\text { Visits } \\
\end{array}$ \\
\hline $\begin{array}{c}0.0021 \\
(0.0012)\end{array}$ & $\begin{array}{l}-0.0114 \\
(0.0043)\end{array}$ & $\begin{array}{l}-0.0841 \\
(0.0496)\end{array}$ \\
\hline
\end{tabular}

\begin{tabular}{|c|c|c|}
\hline \multicolumn{3}{|c|}{ Paternal Characteristics } \\
\hline Father & & Father's \\
\hline Present & Father's Age & Education \\
\hline-0.0001 & -0.2252 & -0.0925 \\
\hline$(0.0047)$ & $(0.0533)$ & $(0.0224)$ \\
\hline
\end{tabular}

Notes: Table gives estimated discontinuities in the specified outcome in mother's birthday at the school entry date. Group-level standard errors in parentheses. For details on sample and estimation, see text. 


\section{Table 3. Effects of Female Education on Infant Health}

\begin{tabular}{|c|c|c|c|}
\hline & California & Texas & Pooled \\
\hline Low Birthweight & $\begin{array}{c}0.0022 \\
(0.0149)\end{array}$ & $\begin{array}{c}0.0183 \\
(0.0111)\end{array}$ & $\begin{array}{r}0.0126 \\
(0.0089) \\
{[0.75]}\end{array}$ \\
\hline Prematurity & $\begin{array}{c}0.0002 \\
(0.0209)\end{array}$ & $\begin{array}{c}0.0076 \\
(0.0133)\end{array}$ & $\begin{array}{r}0.0055 \\
(0.0112) \\
{[0.09]}\end{array}$ \\
\hline Infant Death & NA & $\begin{array}{l}-0.0055 \\
(0.0042)\end{array}$ & NA \\
\hline
\end{tabular}

Notes: Delta-method group-level standard errors in parentheses. Test of overidentifying restrictions (distributed chi-square with 1 degree of freedom under the null) reported in brackets for pooled estimates. 


\section{Table 4. Tests of Overidentification: Continuity of Baseline Characteristics}

\section{California}

\begin{tabular}{|c|c|c|c|c|}
\hline \multicolumn{5}{|c|}{ Maternal Characteristics } \\
\hline Hispanic & Black & Black* & $\begin{array}{l}\text { Low } \\
\text { Birthweight* }\end{array}$ & Prematurity* \\
\hline $\begin{array}{l}-0.0033 \\
(0.0105)\end{array}$ & $\begin{array}{l}-0.0015 \\
(0.0038)\end{array}$ & $\begin{array}{l}-0.0003 \\
(0.0033)\end{array}$ & $\begin{array}{l}-0.0008 \\
(0.0013)\end{array}$ & $\begin{array}{l}-0.0029 \\
(0.0063)\end{array}$ \\
\hline \multicolumn{5}{|c|}{ Grandparental Characteristics* } \\
\hline Native & & Child & \multicolumn{2}{|c|}{ Age at Childbirth } \\
\hline Born & Parity & Mortality & Mother & Father \\
\hline $\begin{array}{c}0.0027 \\
(0.0076)\end{array}$ & $\begin{array}{c}0.0095 \\
(0.0148)\end{array}$ & $\begin{array}{c}0.0018 \\
(0.0055)\end{array}$ & $\begin{array}{c}0.0388 \\
(0.1034)\end{array}$ & $\begin{array}{c}0.0692 \\
(0.1002)\end{array}$ \\
\hline \multicolumn{5}{|c|}{ Texas } \\
\hline \multicolumn{5}{|c|}{ Maternal Characteristics } \\
\hline Hispanic & Black & Black* & $\begin{array}{c}\text { Low } \\
\text { Birthweight* }\end{array}$ & Prematurity* \\
\hline $\begin{array}{c}0.0055 \\
(0.0056)\end{array}$ & $\begin{array}{c}0.0025 \\
(0.0042)\end{array}$ & $\begin{array}{c}0.0021 \\
(0.0023)\end{array}$ & $\begin{array}{c}0.0004 \\
(0.0031)\end{array}$ & $\begin{array}{l}-0.0078 \\
(0.0050)\end{array}$ \\
\hline \multicolumn{5}{|c|}{ Grandparental Characteristics* } \\
\hline Native & & Child & Age at & dbirth \\
\hline Born & Parity & Mortality & Mother & Father \\
\hline $\begin{array}{l}-0.0001 \\
(0.0074)\end{array}$ & $\begin{array}{c}0.0027 \\
(0.0161)\end{array}$ & $\begin{array}{c}0.0006 \\
(0.0015)\end{array}$ & $\begin{array}{l}-0.0175 \\
(0.0399)\end{array}$ & $\begin{array}{l}-0.0357 \\
(0.0578)\end{array}$ \\
\hline
\end{tabular}

Notes: Table presents estimated discontinuities in baseline characteristics using information on all first-time mothers in our main data, as well as the 1969-1988 public-use Natality Detail Files. Estimates from public-use files indicated by asterisk. Group-level standard errors in parentheses. 


\section{Table 5. Heterogeneity in Effects}

\section{of School Entry Policies}

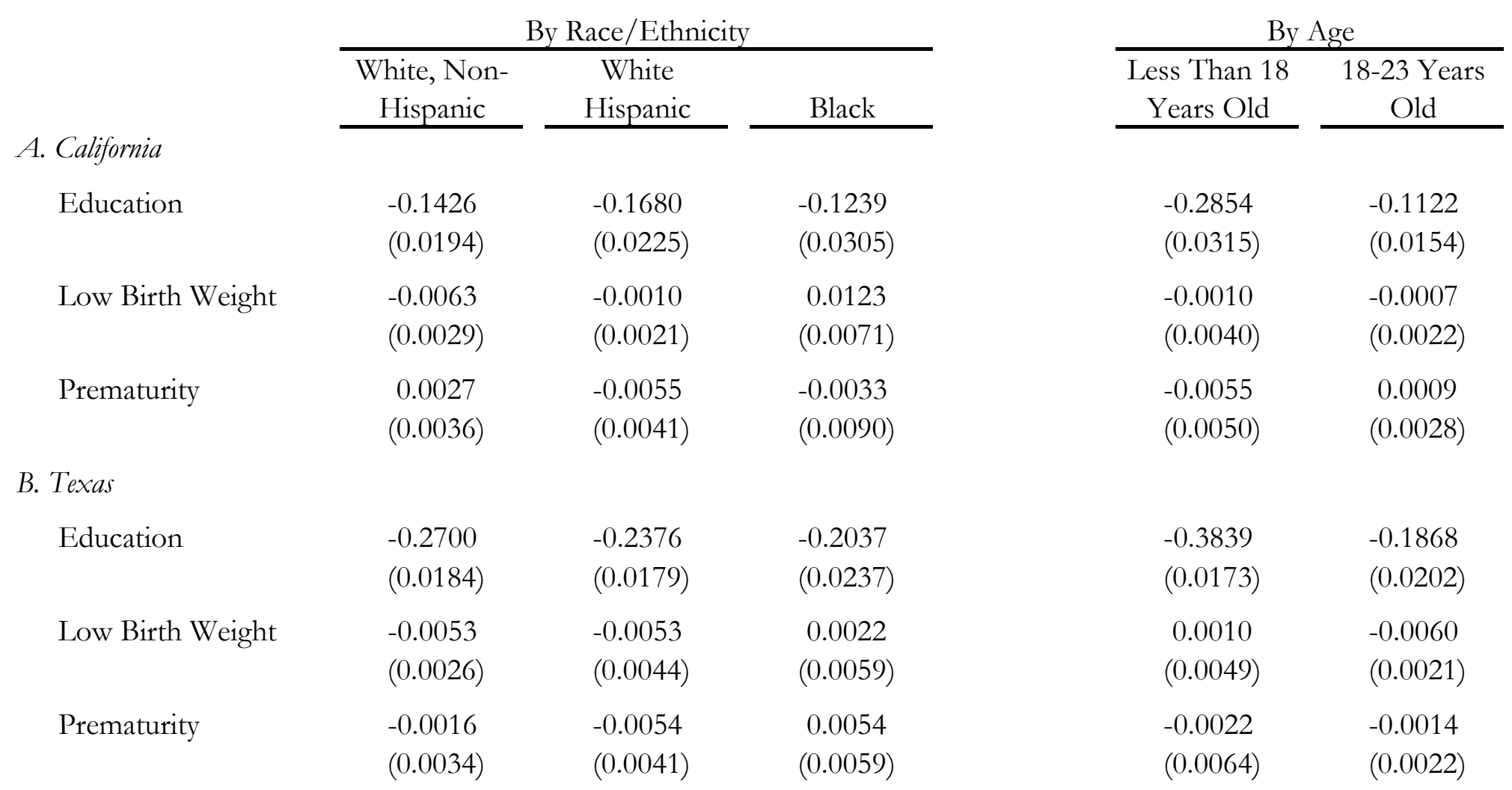

Notes: Group-level standard errors in parentheses. Bandwidth of 70 days. 


\section{Appendix Figure 1. Robustness to Alternative Bandwidths}

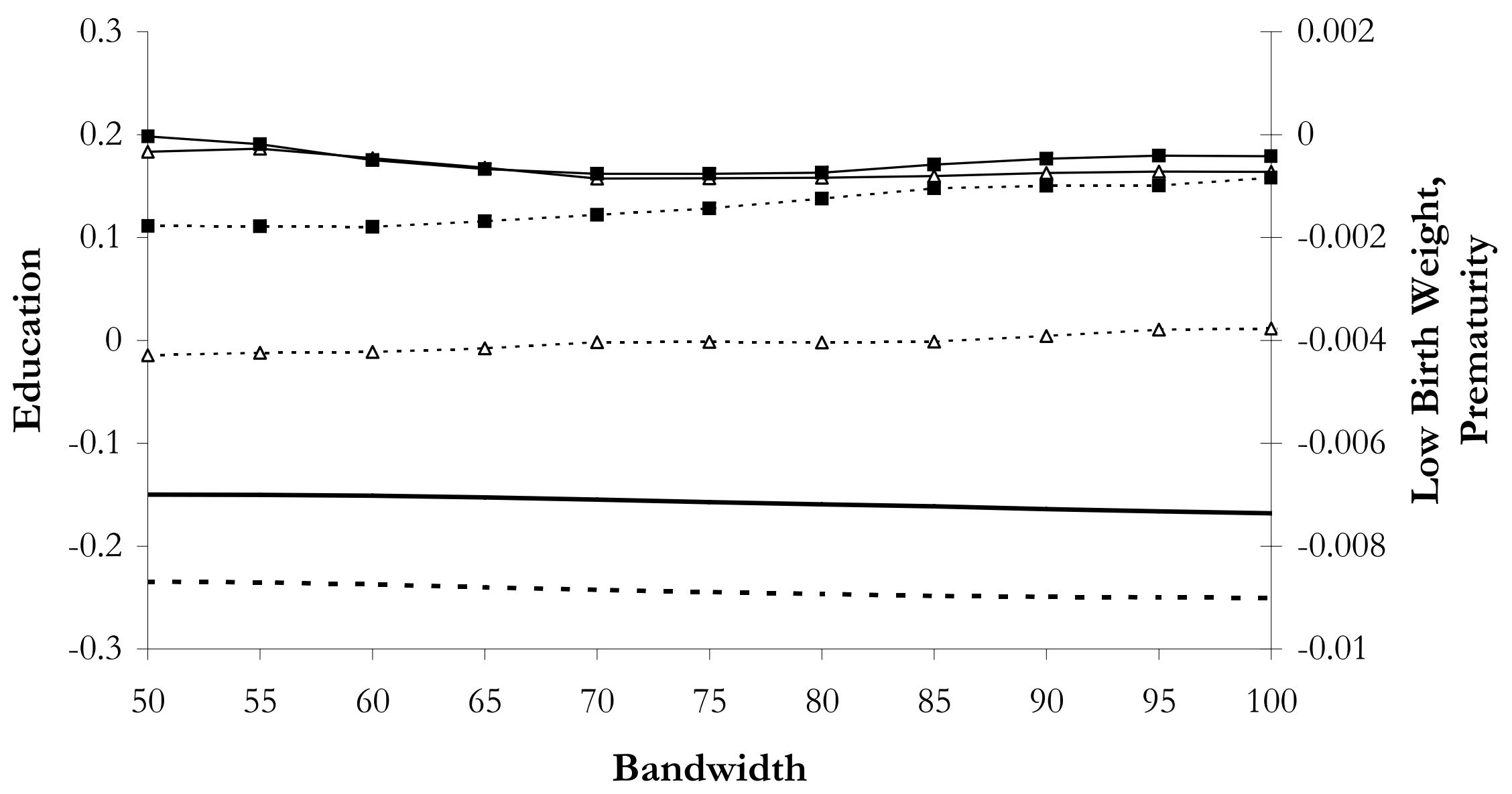

\begin{tabular}{ll|}
\hline$\longrightarrow$ Education, CA & $-\cdots$ Education, TX \\
$\longrightarrow$ Low Birth Weight, CA & $\cdots \Delta \cdot$ Low Birth Weight, TX \\
$\longrightarrow$ Prematurity, CA & $\cdots \cdot \cdots$ Prematurity, TX \\
\hline
\end{tabular}




\section{Appendix Table 1. Bandwidth Selection}

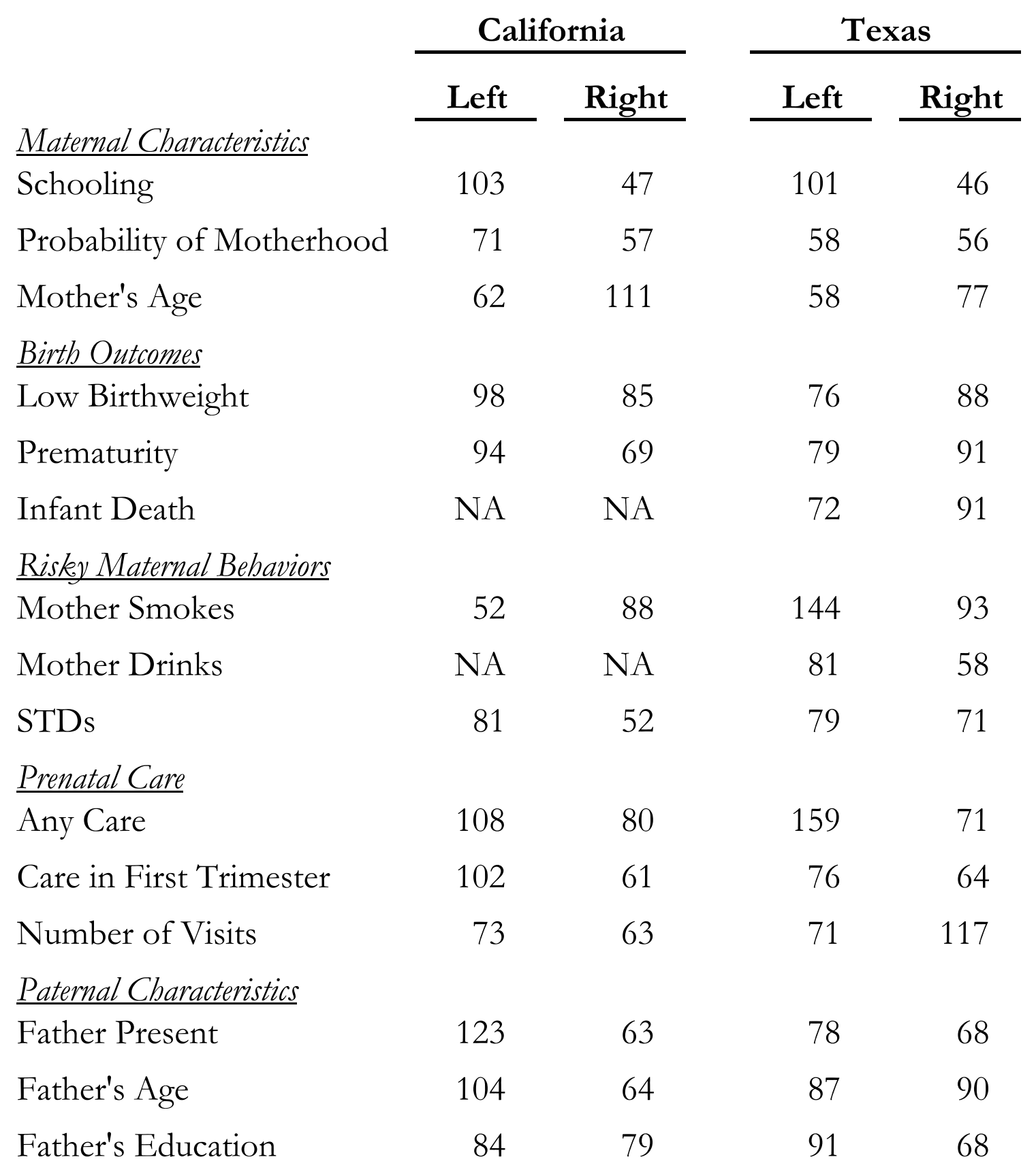

Note: Table presents automatic bandwidth estimates. See text for discussion. 